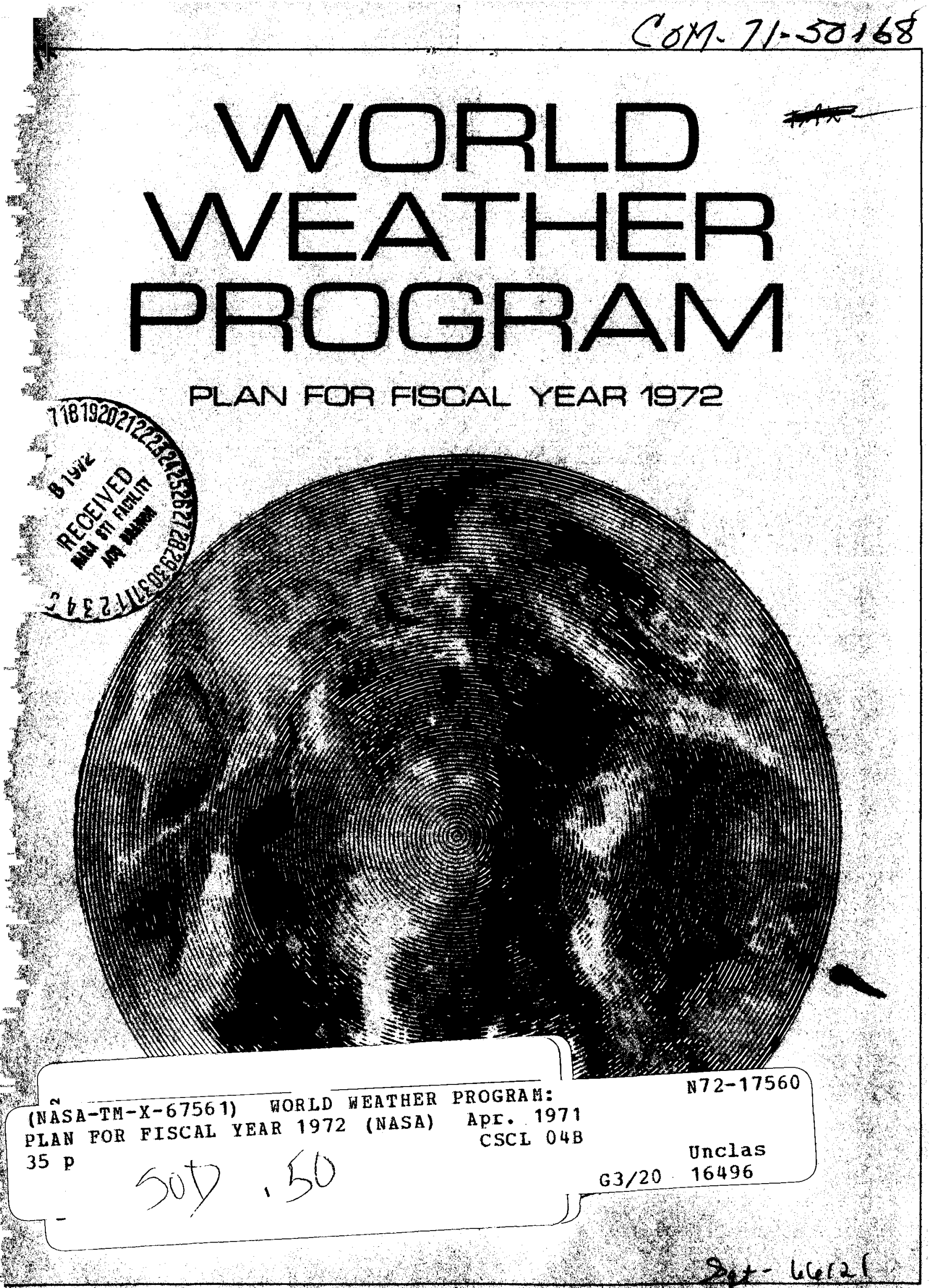




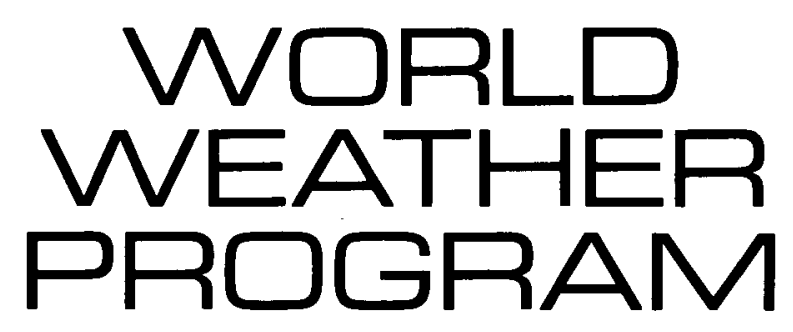

PLAN FOR FISCAL YEAR 1972

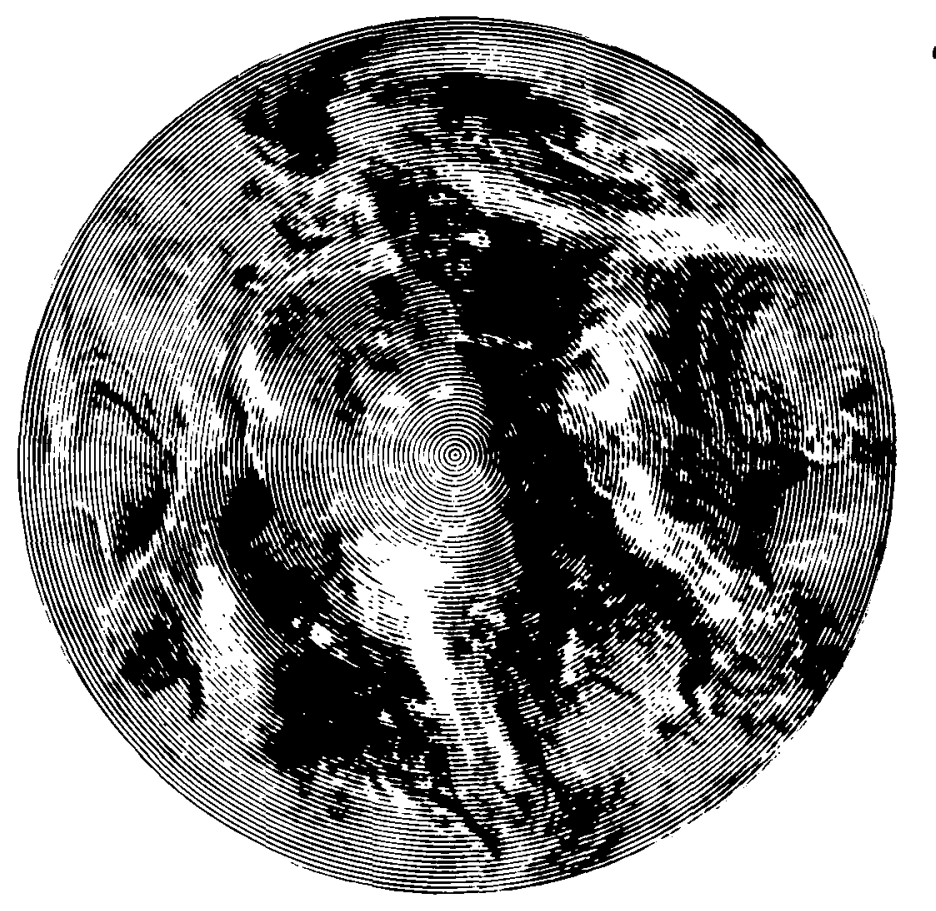

DEPARTMENT OF COMMERCE DEPARTMENT OF DEFENSE DEPARTMENT OF STATE DEPARTMENT OF TRANSPORTATION ENVIRONMENTAL PROTECTION AGENCY ATOMIC ENERGY COMMISSION NATIONAL AERONAUTICS AND SPACE ADMINISTRATION NATIONAL SCIENCE FOUNDATION 
For sale by the Superintendent of Documents, U.S. Government Printing Office, Washington, D.C., 20402. Price 50 cents. 


\section{To the Congress of the United States}

Through the World Weather Program, the nations of the world are combining their efforts to gain new knowledge of the global atmosphere, provide better weather forecasts and warnings to all countries, and assess the damage man has inflicted upon the earth's atmosphere.

I am pleased to report that the Program is making significant progress which will enhance the comfort, health, safety, and economic well-being of men everywhere:

- Satellite technology is being used with increasing effectiveness to gather global information for earlier, more accurate predictions and warnings of hazardous weather.

-New stations are being established for long-term measurement of atmospheric change.

- Computers have been programmed to determine the effect of pollution upon the atmosphere.

-A major international experiment in the Atlantic Ocean is being prepared under the Global Atmospheric Research Program. During the past year many nations, including the United States, have indicated their support of this tropical experiment and have made tentative commitments to provide ships, aircraft, satellites, and other observing facilities. Linked with an increased computer capability to assess and integrate results, this experiment should be an important step toward attaining a true understanding of the global atmosphere.

The scientific understanding which will be developed by the World Weather Program is critical to the solution of environmental problems which are of immense concern to all nations.

Senate Concurrent Resolution 67 of the 90th Congress recognizes the importance of vigorous U.S. participation in the World Weather Program. In accordance with that Resolution, I am transmitting this annual report, describing the most significant activities of the Program and the planned participation of Federal agencies in the Program for the coming fiscal year.

THE WHITE HOUSE

April 1971

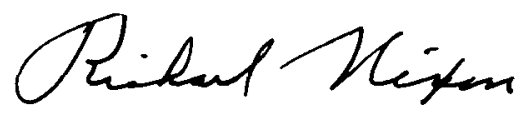




\section{Foreword}

A vital part of man's environment is the atmosphere. Those atmospheric phenomena which we consider under weather and climate have an all-pervading influence on human affairs. The World Weather Program must provide the information needed for the protection of man against the hazards of nature and for the determination of the effects of man on the environment.

The World Weather Program has far reaching goals whose achievement requires the full cooperation and participation of the nations of the world. The goals are:

- To improve the national weather services through increasing the accuracy and extending the time range and scope of weather predictions.

- To develop tools for assessing the consequences to global environmental quality of man's pollution of the atmosphere, including: Mathematical modeling and simulation of the global atmosphere. Monitoring of the composition of the atmosphere in relation to global effects.

- To determine the feasibility of large-scale weather modification and the consequences of human interference with weather processes.

- To establish new dimensions of international joint activity and cooperation, building with advancing technology to meet the need of nations for services concerning atmospheric conditions.

To achieve the goals of the World Weather Program, the nations of the world must:

$\square$ Continue to improve the operational global weather observing network and the communications and processing systems. 
Conduct a comprehensive program of research focused on acquiring a better understanding of the physical processes and the compositional variation of the atmosphere to be incorporated into mathematical models, and on relating this understanding to the operational system.

Develop a new technology for observing the atmosphere, for communicating and processing atmospheric information into products and techniques, and for integrating this technology into the operational system.

These three areas - the World Weather Watch, the Global Atmospheric Research Program, and the Systems Design and Technological Development Program - comprise the World Weather Program.

This World Weather Program for FY 72 describes the U.S. effort to bring about an improvement in the national weather services through advances in science and technology and an expanded program of international cooperation.

This Plan is divided into four sections. The activities of the past year in the Global Atmospheric Research Program are highlighted in the first section. A narrative on the World Weather Program Plan follows in the next section, and the third section contains specific information on the applicable U.S. programs for FY 72. The last section is a fiscal summary of these programs. 


\section{Contents}

page

Foreword

iv

1. 1970—YEAR OF DECISION FOR THE GLOBAL ATMOSPHERIC

RESEARCH PROGRAM .................................................................. 1

Introduction ............................................................................... 1

National Decisions ............................................................................ 1

International Decisions .................................................................. 3

2. WORLD WEATHER PROGRAM PLAN ..................................................... 6

World Weather Watch ...................................................................... 6

Global Atmospheric Research Program ........................................... 15

Systems Design and Technological Development ................................. 18

3. THE UNITED STATES PROGRAM FOR FISCAL YEAR $1972 \ldots \ldots \ldots \ldots . . . . . . . . . . . . . .22$

World Weather Watch Implementation ............................................ 22

Global Atmospheric Research Program ............................................ 23

Systems Design and Technological Development .............................. 25

4. FISCAL SUMMARY ....................................................................... 29 


\section{1970-Year of Decision for the Global Atmospheric Research Program}

The Global Atmospheric Research Program (GARP) is an international co- INTRODUCTION operative research effort aimed at increasing our understanding of the general circulation of the atmosphere and providing the mathematical and physical basis for long-range prediction, for determination of the feasibility of large-scale climatic modification, and for assessment of the consequences to global environmental quality of man's pollution of the atmosphere. Vigorous participation by the United States in this Program is a unique opportunity to realize, through a coherent international program, benefits of pervasive importance.

The year 1970 will stand as one of special significance to GARP. Major decisions, both nationally and internationally, were taken during the year to conduct cooperative international experiments supporting this vital Program. Although there are a number of proposed experiments, these decisions focused on the implementation of a tropical experiment in the Atlantic Ocean in 1974 and a global experiment in 1976-77. In addition, major decisions were made nationally to increase substantially the computer power required for the conduct of a larger spectrum of mathematical modeling and simulation experiments in preparation for the GARP field activities and for expanded fundamental research.

The main scientific thrust of the tropical experiment is to understand the mechanism whereby massive cloud clusters in the tropics transform and redistribute the energy of the tropics for subsequent transport to middle and high latitudes by large-scale circulations. This mechanism is an important link in the energy cycle of the atmosphere for maintaining global circulation. In addition, the tropical experiment will provide greater insight into the atmospheric processes occurring in an area which is a recognized breeding ground for tropical storms and hurricanes that subsequently affect the United States and neighboring countries.

The scientific objective of the global experiment is to provide the necessary data for developing, testing, and improving mathematical models. Models are fundamental tools for testing theories of the long-term behavior of the atmosphere and applying results toward improved and extended predictions.

Nationally, Federal agencies working in concert with the National Academy of NATIONAL Sciences moved forward during the past year with the identification of key DECISIONS scientific and technological problems and with the formulation of a program of action to solve them. Early in 1970, the Federal Committee for Meteorological Services and Supporting Research forwarded recommendations to the Secretary of Commerce on the extent of U.S. participation in GARP and on the agency responsibilities for various parts of this participation. Further, the Committee recognized that participation by universities is essential. 
Global observational experiments, mathematical modeling, and intensive field investigations are the major components of GARP. Several Federal agencies participate to a greater or lesser degree in one or all of these activities.

Through a Presidential directive following enactment of Senate Concurrent Resolution 67, the Secretary of Commerce has been assigned the responsibility to bring all agencies together in joint participation in the U.S. portion of the World Weather Program. Thus, overall coordination and planning of this Program rests with the Department of Commerce. Within this Department, the National Oceanic and Atmospheric Administration (NOAA) has been tasked with this responsibility.

Global Polar-orbiting and geostationary satellites are vital parts of the World Weather Observational Watch and will be used in future global observational experiments for GARP, in Experiments addition to all available conventional platforms. The National Aeronautics and Space Administration (NASA) has been assigned lead agency responsibility for the detailed planning for the First GARP Global Experiment (FGGE). NOAA is providing assistance to NASA in the development of this plan. As the planning proceeds, it is also expected that other agencies will participate in this joint effort.

Mathematical The second major component of GARP is mathematical modeling. Here, Modeling observing systems simulation studies and model development are the two important aspects. The National Science Foundation (NSF) has been assigned the lead agency responsibility for the coordination of U.S. efforts in observing systems simulation studies. These studies will evaluate, by means of computer techniques and using already available mathematical models, the prediction capabilities of alternate global observing systems based upon the characteristics of the systemssuch as the variables measured, the accuracy of the measurements, the density and spatial distribution of the observations, and the frequency of the reports. A maximum interagency effort is required on this important problem. The National Center for Atmospheric Research (NCAR), sponsored by NSF, conducts studies of this nature. NASA also participates to a substantial degree in these studies at its Goddard Institute for Space Studies. Further, NOAA is active in related work at its Geophysical Fluid Dynamics Laboratory.

Defense, NOAA, and NSF support major efforts in mathematical model development. Because mathematical modeling is basic to all aspects of atmospheric research from small convective motions to global circulations, a concerted effort by all agencies is needed. Within the spectrum of model development, Defense places emphasis on intensive investigations of large-scale climatic modification; NOAA focuses attention on experimental applications and basic modeling research on large- and medium-scale circulations; and NSF emphasizes modeling of turbulence and convective phenomena. NASA also performs some modeling research in support of its primary emphasis on observing systems simulation studies.

Tropical NOAA is assigned responsibility for establishment of a project office for the Experiment overall data management plan, the operational management and the implementation of the tropical experiment, and a data acquisition test to be conducted in conjunction with the experiment. NASA will establish a supporting project office for the specialized data management plan and for the implementation and operational management of the data acquisition test. In carrying out these responsibilities, the assistance, advice, and active support of all other interested agencies are essential to the success of the experiment. Other planned field experiments, such as for clear air turbulence, will be coordinated through the Federal Coordinator for Meteorological Services and Supporting Research.

Agency CommitmentsTropical Experiment

Five Federal agencies have tentatively committed resources, such as ships, aircraft, and satellites, to the tropical experiment in the Atlantic. Specific agency contributions are shown in the accompanying chart. 


\begin{tabular}{|c|c|c|c|}
\hline & SHIPS* & AIRCRAFT & SATELLITES \\
\hline DOC & 2 & 1 & NOAA, GOES \\
\hline DOD & 1 & 1 & \\
\hline DOT & 1 & & \\
\hline NASA & & 1 or 2 & $\begin{array}{l}\text { SMS, NIMBUS, } \\
\text { ATS }\end{array}$ \\
\hline NSF & 1 & 1 or 2 & \\
\hline
\end{tabular}

*Plus support vessels (e.g., buoy tender, fast courier ships, and resupply ships).
Tentative Federal agency commitments for the tropical experiment (Federal Committee, Jan. 1970)

In addition to these resources, other anticipated agency commitments include the establishment of a project office, university support, participation in international bodies, computer capability, data management, technological development (such as buoys and balloons), logistics, and telecommunications.

The agency responsibilities for U.S. participation in GARP and the specific commitments for the tropical experiment were formulated by the Federal Committee for Meteorological Services and Supporting Research in early 1970. This participation in GARP formed the basis for the U.S. positions at the international meetings on GARP held in Brussels (March 1970) and in London (July 1970).

A major international planning conference on GARP was held in Brussels during March 1970. At the conference, 25 nations considered the scientific plans and provided information on the scope of their participation. To meet the scientific objectives, it was proposed internationally to mount an experiment in 1974 in the tropical Atlantic. The area would extend approximately from the west coast of Latin America eastward to Ethiopia in Africa between latitudes $10^{\circ} \mathrm{S}$. and $20^{\circ} \mathrm{N}$. (see accompanying chart). For the observational network, eight nations of the world, including the United States, have tentatively pledged extraterritorial support in the form of satellites, ships, and aircraft (see accompanying chart). Other

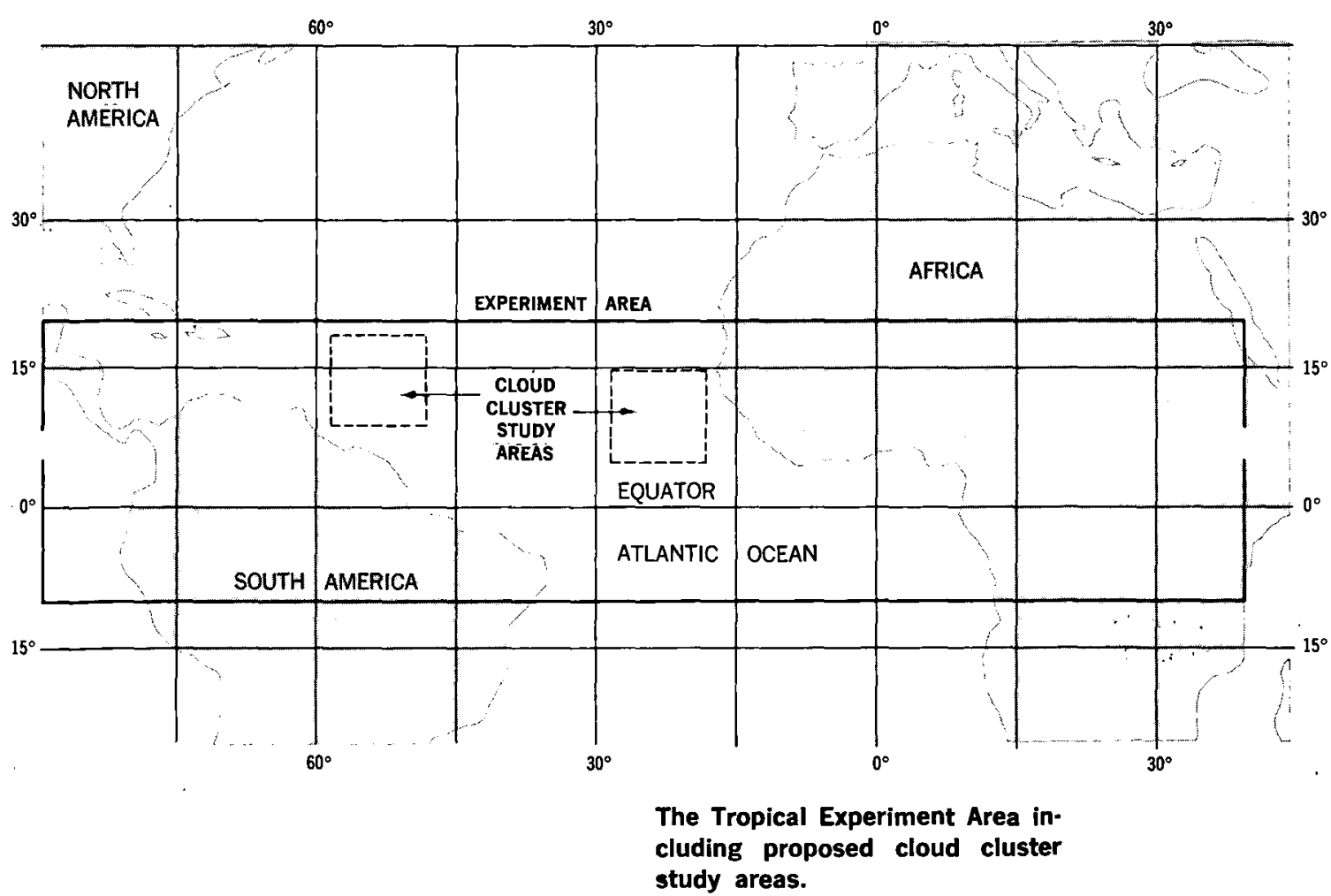

The Tropical Experiment Area including proposed cloud cluster study areas.

\section{INTERNATIONAL} DECISIONS 
potential observing facilities, such as ships of opportunity, commercial aircraft, buoys, tethered and carrier balloons, and additional upper air observations were also pledged.

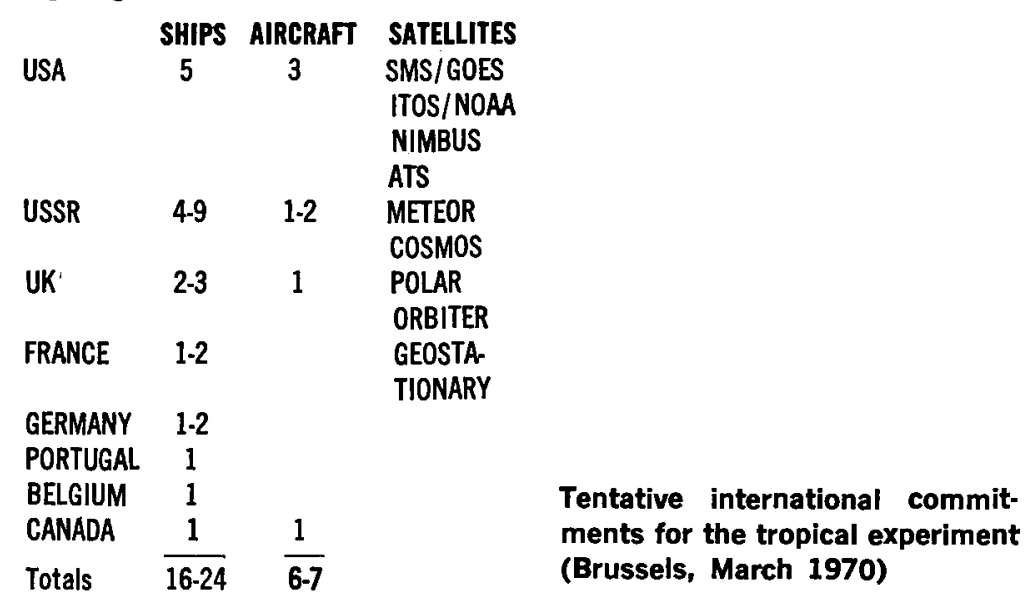

Management The need for collaboration with the oceanographic community has been stressed Principles - to permit full advantage to be taken by the oceanographers of the unique conTropical centration of research ships to make observations for their own purposes.

Experiment To conduct the tropical experiment in 1974, the following target dates have been adopted:

$\square$ Complete the scientific design of the experiment by September 1971.

$\square$ Designate a specific date and time frame for the experiment by September 1971.

$\square$ Make firm national commitments by January 1972 .

Institutional arrangements are necessary to insure the success of the experiment. These arrangements, involving organization and management, are required to carry out the detailed scientific, engineering, and operational planning, to reach agreements, and to commit resources efficiently and effectively. A Tropical Experiment Board (TEB) has been proposed to provide management for the experiment. This Board would be concerned primarily with the planning and operation of extraterritorial observing facilities, such as satellites, ships, and aircraft, and with the processing and analysis of the data. The TEB will be composed of countries contributing substantially to the experiment.

International organization for the tropical experiment (London, July 1970)

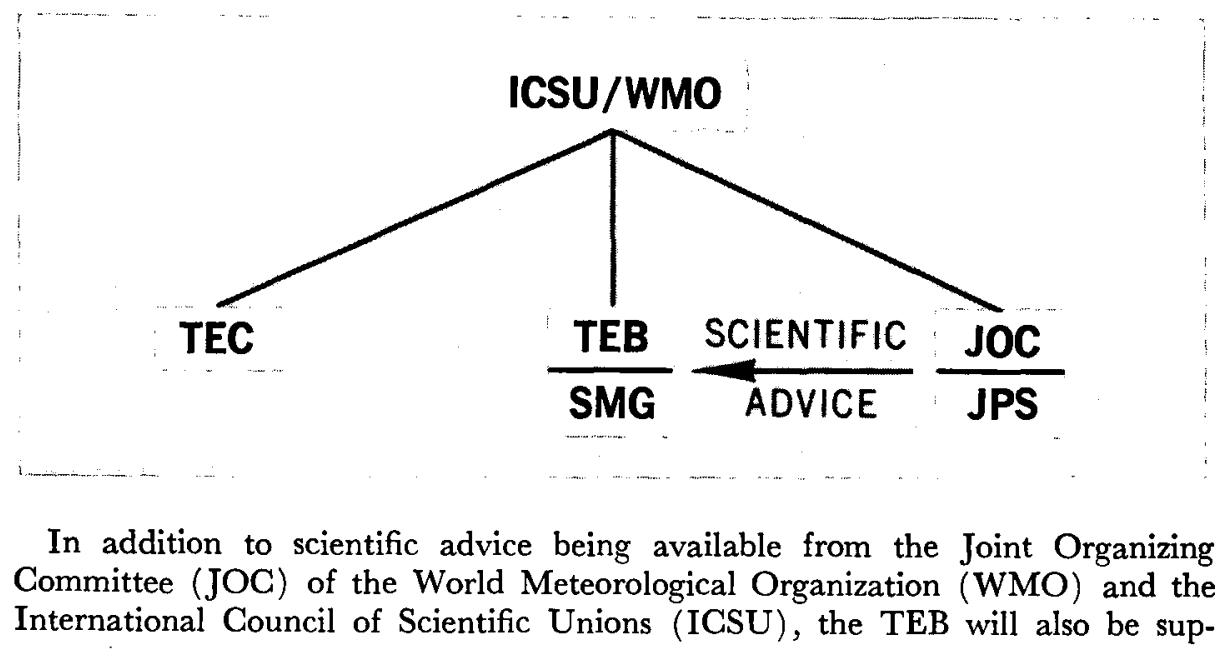


ported by a full-time staff, known as the Scientific Management Group (SMG), with competence in tropical meteorology, atmospheric modeling, systems analysis, data processing, engineering design, and management. The SMG would be headed by a director and a deputy who together might carry out the functions of scientific leader and project manager. It was agreed that the best place for the location of the SMG would be within a major meteorological research institute where there would be a scientific atmosphere and adequate supporting facilities, including access to a powerful computer.

In addition to the TEB, there would be a Tropical Experiment Council (TEC) composed of all countries over whose territory the experiment will take place as well as those countries which are members of the TEB. The main responsibilities of the TEC, with respect to the tropical experiment, are to review the planning progress, to improve the World Weather Watch facilities in the area of the experiment, and to apply the results of the experiment for improved forecasting in the tropics. An accompanying chart shows the international organization for the tropical experiment.

Although the major thrust of the Brussels' Conference was on the tropical Planning experiment, the First GARP Global Experiment (FGGE) was also reviewed and for the further plans for this Experiment were formulated. The Conference concluded First that the success of the FGGE is dependent upon the achievement of the objec- GARP Global tives of the World Weather Watch global observing, data processing, and tele- Experiment communications systems. The Conference recognized that the availability of a large computer capability is an essential requirement for the FGGE and that the implementation must cover the following needs:

$\square$ Numerical simulation experiments for the design of the required observational system.

Global analysis to determine the effectiveness of the system as a whole.

$\square$ Testing and intercomparisons of various atmospheric models both during and for some time after the period of the Experiment.

The management of the FGGE requires special consideration and will not necessarily follow the same pattern as the tropical experiment. The Conference considered that it was premature to establish any definite arrangements for the FGGE. It did, however, invite the Joint Organizing Committee of the WMO and ICSU to:

$\square$ Complete additional planning for the global experiment, including the preliminary developments and tests required;

$\square$ Develop a time schedule for the detailed planning and implementation;

$\square$ Formulate appropriate recommendations; and

$\square$ Report on these matters to the Executive Committees of the WMO and ICSU in approximately 1 year (March 1971).

The Executive Committee of the ICSU at its annual meeting in September|Executive 1970 approved with minor modifications the reports of the 1970 international 'Committee planning meetings on GARP.

In a resolution on GARP, the Executive Committee of the WMO, during its the ICSU and October 1970 session, approved the location of the tropical experiment in the WMO

Atlantic Ocean, the overall scientific concept, and the establishment of the TEG and the TEB.

Major decisions taken in 1970 will have far-reaching impact upon the future course of GARP. The tropical experiment in 1974 has been well charted by these decisions. The foundation for the following global experiment is firmly placed. The accomplishment of these experiments and other related GARP research will, in turn, provide for major advances in the understanding of the atmosphere in which we live, for improved weather prediction, and for enhanced environmental quality in the decade of the 1970's. 


\section{World Weather Program Plan}

WORLD The World Weather Watch, the operational aspect for the World Weather WEATHER Watch Program, is coordinated internationally by the World Meteorological WATCH Organization (WMO), a specialized agency of the United Nations, with 133 Members. The implementation for the Watch is proceeding in 4-year phases, with the first phase being completed at the end of Calendar Year 1971. During this first phase, the major effort in the planning and implementation of the Program was to remedy the more critical deficiencies in the existing international weather system.

The next World Weather Watch Plan is for the period 1972-75. It will be reviewed at the WMO Congress in April of this year. This second phase of the Plan calls for two or three polar-orbiting and four geostationary satellites as an integral part of the Global Observing System. Means would thus be provided for international collection and exchange of meteorological data obtained from the satellites. Completion of the global communication circuits is also proposed as part of this second phase of the Plan. In addition, heavy emphasis is placed on the installation of conventional sounding systems in the tropical land areas. Further, a new dimension is now part of the Plan and is concerned with monitoring of atmospheric pollutants on a global basis. A network of regional and baseline stations has been proposed.

Global Global observations are basic to both the operational and research arms of the Observing World Weather Program. The current network of conventional surface and upper System air observations is being supplemented increasingly by data obtained from meteorological satellites. During the period 1972-75, it will still be necessary, however, to rely on this conventional synoptic network as a primary source of upper air data.

The most urgent need in the Global Observing System is for additional surface and upper air observations in the tropics, the Southern Hemisphere, and the ocean areas of the Northern Hemisphere. The ocean areas are the most critical, but even over land areas, there remain significant gaps in the observational networks in certain portions of Brazil, in the desert regions of North Africa and Southwest Asia, and in part of the Southwest Pacific. Recent experimental work with meteorological satellites has shown that it is possible to measure the sea-surface temperature with an accuracy of about $\pm 1^{\circ} \mathrm{C}$. There have also been outstanding successes with research satellites in deriving vertical temperature and humidity profiles by the inverse radiation technique and in deducing the wind field by the measurement of cloud displacements. Based upon these results, future operational meteorological satellites will probably be able to remedy many of the present observational deficiencies, at least in regard to the upper air and sea-surface temperature data needed for global analyses by numerical methods. 
Antenna installation of a U.S. Voluntary Assistance Programsupported APT station on Lusaka, Zambia, airport.

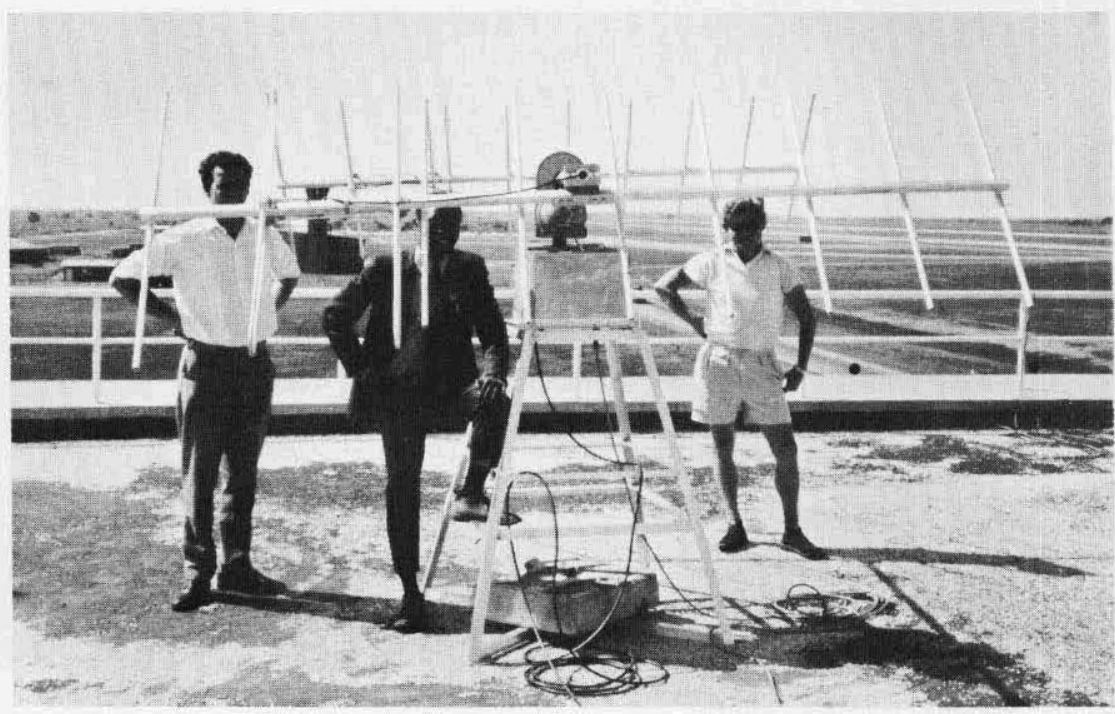

The United States has, through its contributions to the WMO Voluntary Assistance Program, provided ten sets of ground equipment to meteorological services of other countries throughout the world. Plans are underway to provide additional sets during the next increment of the program in 1971.

SURFACE- The surface network of stations within the United States meets the World BASED Weather Watch criteria of the maximum average spacing of 500 kilometers beOBSERVING SYSTEM

Global Pollution Monitoring Stations tween observing stations on land. Networks to meet national needs may be more to fill the gaps in the surface observational network by new, partly or fully automatic weather-observing stations.

The United States also meets its World Weather Watch upper air observational commitments over the conterminous States. In addition, the Departments of Commerce and Defense operate a substantial number of upper air observing stations overseas. This basic upper air observing effort by this country is integrated with observations by other nations into a global network of about 850 observations that are available as initial data for numerical prediction models.

For global pollution monitoring purposes, both regional and baseline stations are needed. A regional station is intended to document the long-term changes in atmospheric composition caused by changes in regional area land use practices and will measure at least turbidity and certain aspects of precipitation. A baseline station is designed primarily as an observing site to document long-term changes in atmospheric environmental parameters of particular significance to weather and climate with a minimum influence from local or regional factors. These global baseline stations will measure at least carbon dioxide, turbidity, and the constituents of precipitation and dry fallout. The United States presently operates a baseline station at Mauna Loa, supports a second one in New Zealand, and is planning to establish new ones at remote sites in the Arctic and Antarctic to monitor atmospheric pollution. In addition, 10 regional stations will be activated here in the United States this year as a cooperative effort between the Environmental Protection Agency (EPA) and NOAA.

Moving In the surface-based observational program at sea, the recruitment of selected Ships supplementary and auxiliary ships for the WMO Voluntary Observing Ship scheme shows that a continuing increase in the number of ships can be expected through the end of 1971 . However, it is doubtful that the projected increase will 
eliminate the deficiency in coverage in the Southern Hemisphere. The trend toward larger vessels and smaller crews points out the need for the development of automated techniques to obtain and transmit ships' weather reports.

The World Weather Watch Plan calls for at least 100 ships taking upper air observations by the end of 1971 . The United States now has 15 meteorological teams making upper air observations from merchant ships. These shipboard observations are supplemented on a nonroutine basis by the Department of Defense and Coast Guard vessels when at sea.

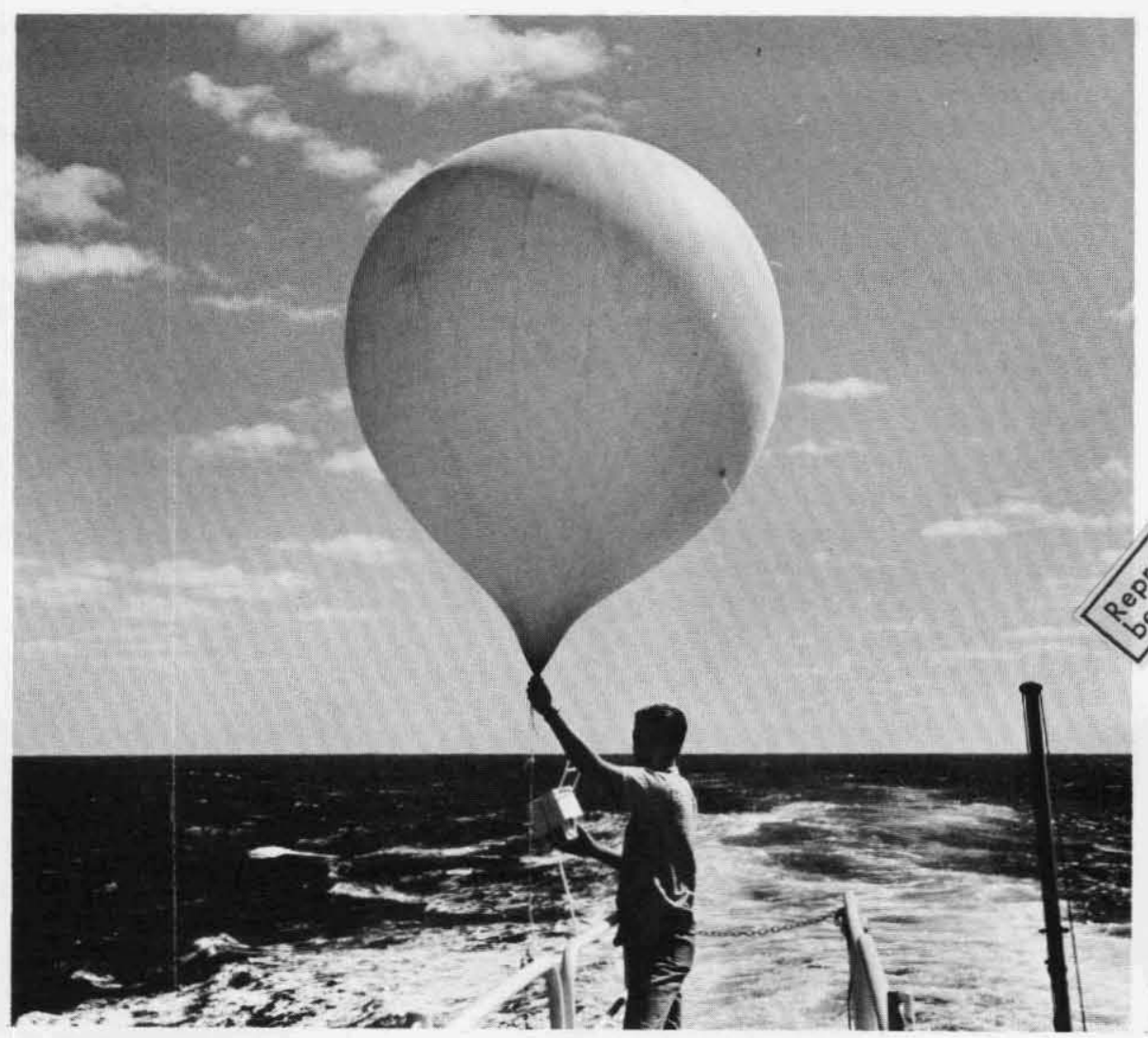

In addition, there are 13 Ocean Station Vessels in the North Atlantic and the North Pacific Oceans which make regular surface and upper air observations. In accordance with the World Weather Watch Plan, these Stations should be maintained without reduction in number or program until such time as completely satisfactory and proven alternative observing systems are available. Studies have been initiated, however, on possible alternative means, such as satellites, of obtaining the meteorological data required for providing service to civil aviation and other users.

To supplement the regular network of 13 Ocean Station Vessels, South Africa has placed a new Ocean Station Vessel in the South Atlantic Ocean for a minimum period of a year. Further, from August to March of each year, the United States will operate a new weather ship off the east coast near the State of New Jersey to provide additional surface and upper air weather observations in support of the U.S. National East Coast Winter Storms Operations Plan. The program began in February 1970 and will be continued. In addition, the U.S.S.R.

\author{
Ocean \\ Station \\ Vessels
}

Observations taken at sea are an important input to the basic data used in weather analysis and forecasting. 
had stationed a weather ship east of the Philippine Islands in the Pacific Ocean from June to August 1970 to provide similar support for typhoon weather observations, and is expected to continue the program on a yearly basis.

Buoys The Department of Commerce, through its National Data Buoy Development Project, is taking steps to satisfy national requirements for data from deep oceans and the coastal areas of North America. In an experiment initiated in early 1970, an engineering model buoy was deployed off the eastern coast of the United States to provide data in support of the National East Coast Winter Storms Operations Plan. This experiment is being continued.

Aircraft Aircraft meteorological reports from civilian and military aircraft provide valuable weather information, particularly over oceans and other data-sparse areas. The Department of Defense conducts daily reconnaissance flights over fixed tracks in remote ocean and uninhabited arctic areas. These flights obtain weather information at flight level and vertically downward to the surface at fixed points along these tracks. On selected flights, aircraft equipped with bathythermograph equipment measure ocean temperatures to a depth of 1,000 feet.

Through utilization of specially equipped aircraft deployed to strategic locations in the Atlantic and Pacific, special aerial reconnaissance flights are often performed several times daily. These flights involve penetrations of existing and suspected tropical hurricanes or cyclones over most of the water areas of the Northern Hemisphere. The Department of Commerce provides supplemental data and reconnaissance backup to the Department of Defense in the Atlantic area. The United States makes available to the world meteorological community all weather information obtained on both the routine sorties and the special tropical storm reconnaissance and surveillance missions.

\section{Aircraft of the WC-130B type pro- vide vital synoptic and storm reconnaissance.}

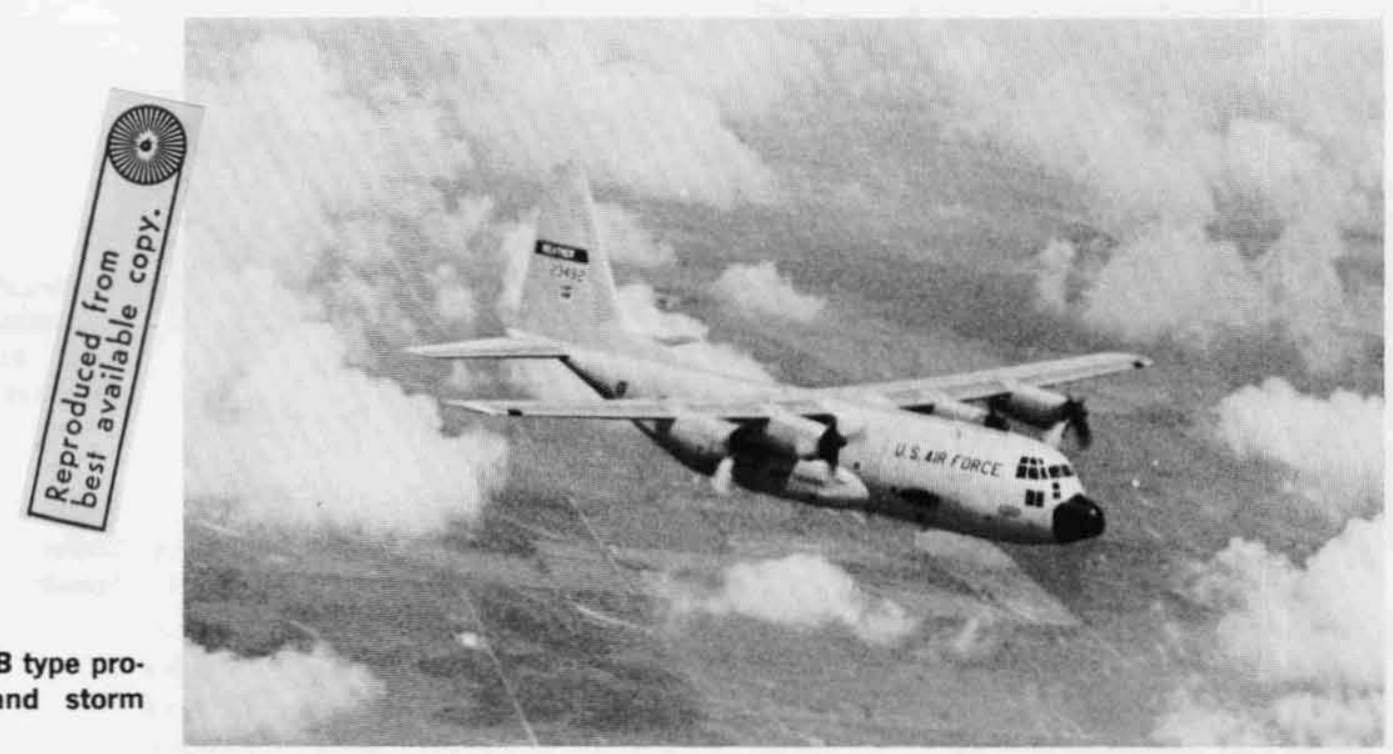

Global Data The Global Data Processing System (GDPS) of the World Weather Watch for Processing the periods 1968-71 and 1972-75 is designed to support the national meteorologSystem ical services of the world with processed meteorological products on a global or regional scale. The System also ensures the processing of data for climatological and research purposes and the storage of data for ready retrieval. The GDPS operates through a system of World, Regional, and National Meteorological Centers. 
The main improvement needed in the GDPS at present appears to be a reduction of the time between receipt of the raw observational data at the Regional and World Meteorological Centers and the availability of the output product to the user. To meet this goal, the installation of computers at all Regional Meteorological Centers is necessary. These installations should be accomplished in conjunction with the education and training of the personnel in the use of these facilities. Once completed, the introduction of digital techniques in data processing would result in a considerable reduction in the time required for the generation and availability of output products.

In accordance with the World Weather Watch Plan, World Meteorological WORLD Centers (WMC) are in operation at Melbourne, Australia; Moscow, U.S.S.R.; and Washington, D.C. One of the most important functions of these Centers is the provision of meteorological analyses and forecasts on a global scale. The WMC Washington is composed of the National Meteorological Center (NMC) and the National Environmental Satellite Service (NESS) of NOAA. The National Climatic Center (NCC) of the Department of Commerce is the central archival processing and service center for the WMC Washington.

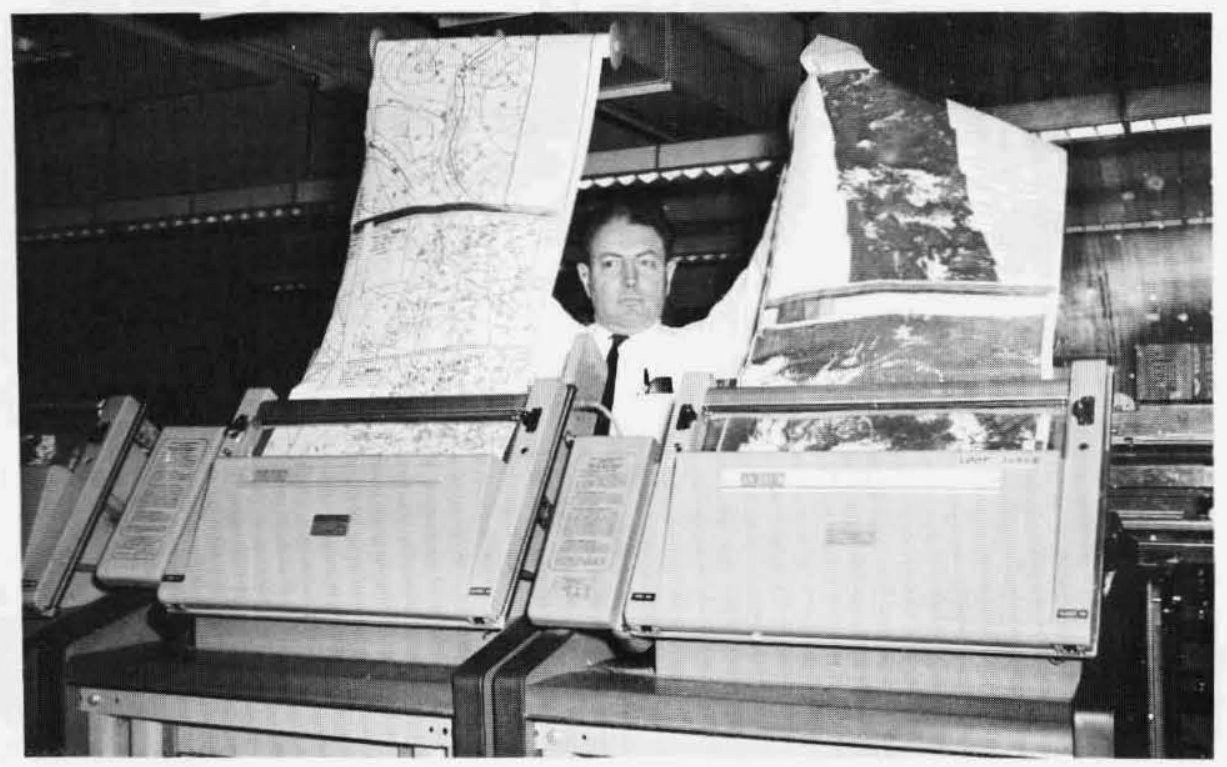

WMC Washington satellite pictures and weather charts being

\section{METEOROLOGICAL}

To improve the capability of the United States to meet its operational responsibilities both nationally and internationally under the World Weather Watch Plan, the Department of Commerce proposes to convert to fourth-generation computers at the WMC Washington. On a typical day, the WMC processes more than 40,000 surface observations, 2,000 ship reports, 1,000 upper air soundings, 2,000 aircraft reports, and global cloud cover data.

The World Weather Watch Plan lists 21 Regional Meteorological Centers (RMC) as forming the initial basis for the implementation of the RMC system. With one exception, the Centers have been implemented and are preparing meteorological analyses and forecasts on a regional scale for assigned areas. The continued development of the Centers and their conversion to computer techniques for generating output products will result in an increase in RMC support provided to the National Meteorological Centers (NMC). disseminated to users.

CENTERS

disseminated to users.

REGIONAL

METEOROLOGICAL

\section{CENTERS}




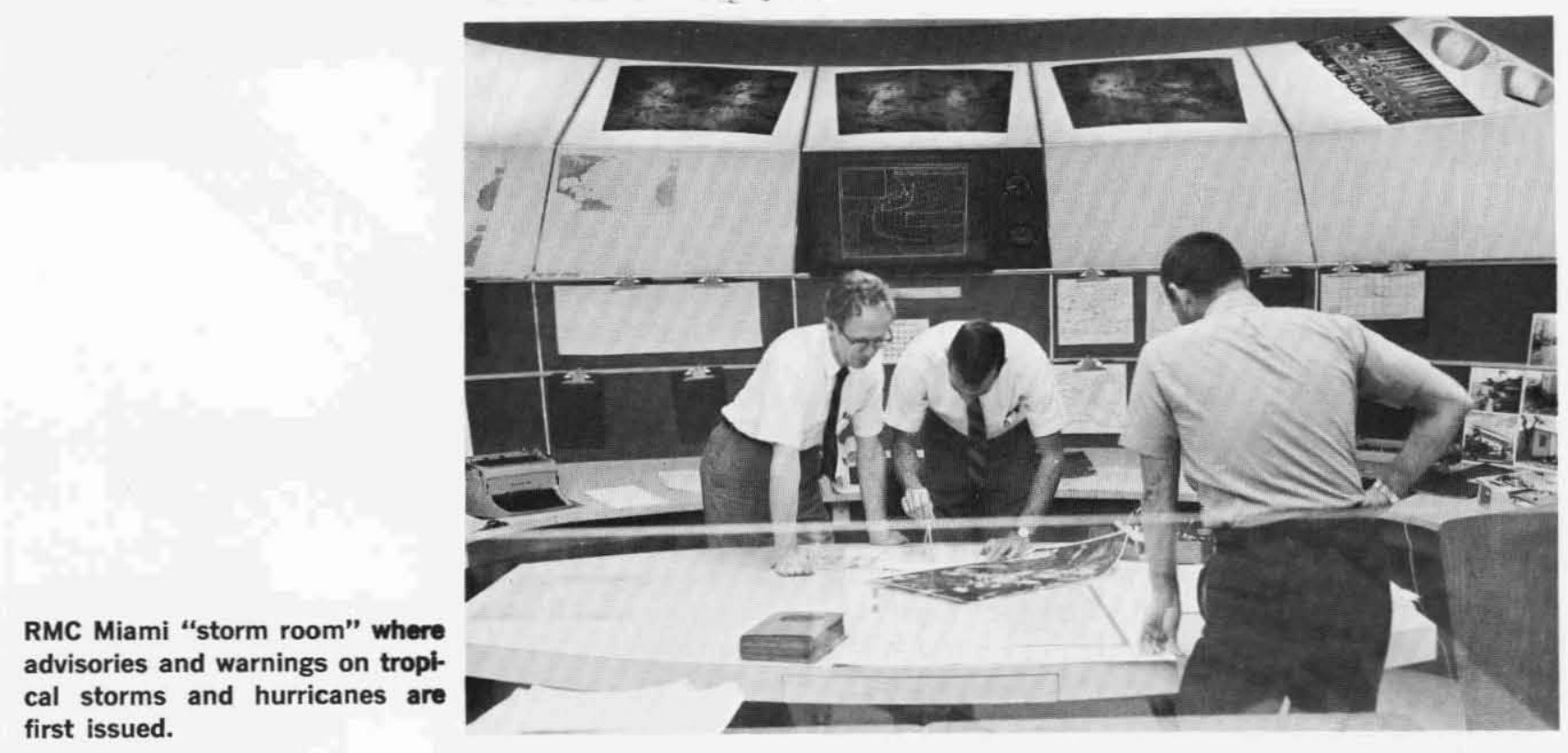

first issued.

Global

Telecommunications System
NATIONAL The World Weather Watch Plan emphasizes that each country should have an METEOROLOGICAL. NMC adequately manned and equipped to derive the full benefits of the informaCENTERS tion available from the global observing and data processing systems. In the United States, the National Meteorological Center (NMC) of NOAA is an integral part of the Washington WMC. The main projects currently underway by the Department of Commerce in support of the WMC are those to strengthen the data processing activities; to improve and increase the forecasting services to aviation, agriculture, and hydrology; to upgrade communications capability; and to improve numerical weather prediction models.

The Global Telecommunications System (GTS) is the backbone of the World

The U.S. operates one RMC in Miami, Fla., from which 18 countries have requested processed meteorological information in support of their national commitments. In meeting this requirement, the RMC provides daily charts of analyses and forecast information covering the tropical latitudes in its area of responsibility.

Both RMCs and WMCs provide support to many specialized activities. The main support to aviation activities is exerted through the area forecast system. Information describing the state of sea, sea ice, and sea-surface temperature is now available to support shipping and other marine activities in the safe and efficient conduct of their operations.

Many of the products required for the purpose of hydrological forecasting (for example, charts showing such items as the extent of snow and ice cover, precipitation areas, freezing level, forecasts of precipitation amount, and maximum and minimum temperatures) are now prepared for the area of the United States on a regular basis by the WMC Washington and will continue. In addition, a substantial part of the requirements for agriculture is met by the WMC Washington for the area of the United States as a routine operation. The WMC Washington support of these specialized services internationally is in providing global-scale circulation analyses and predictions.

Weather Watch providing for the collection, exchange, and distribution of observational and processed data among the WMCs, RMCs, and NMCs. Through 25 Regional Telecommunication Hubs, the GTS serves three WMCs, 21 RMCs, and 147 NMCs or Centers with similar functions worldwide. Existing shortcomings in the GTS, especially in the Southern Hemisphere, are often the major underlying 


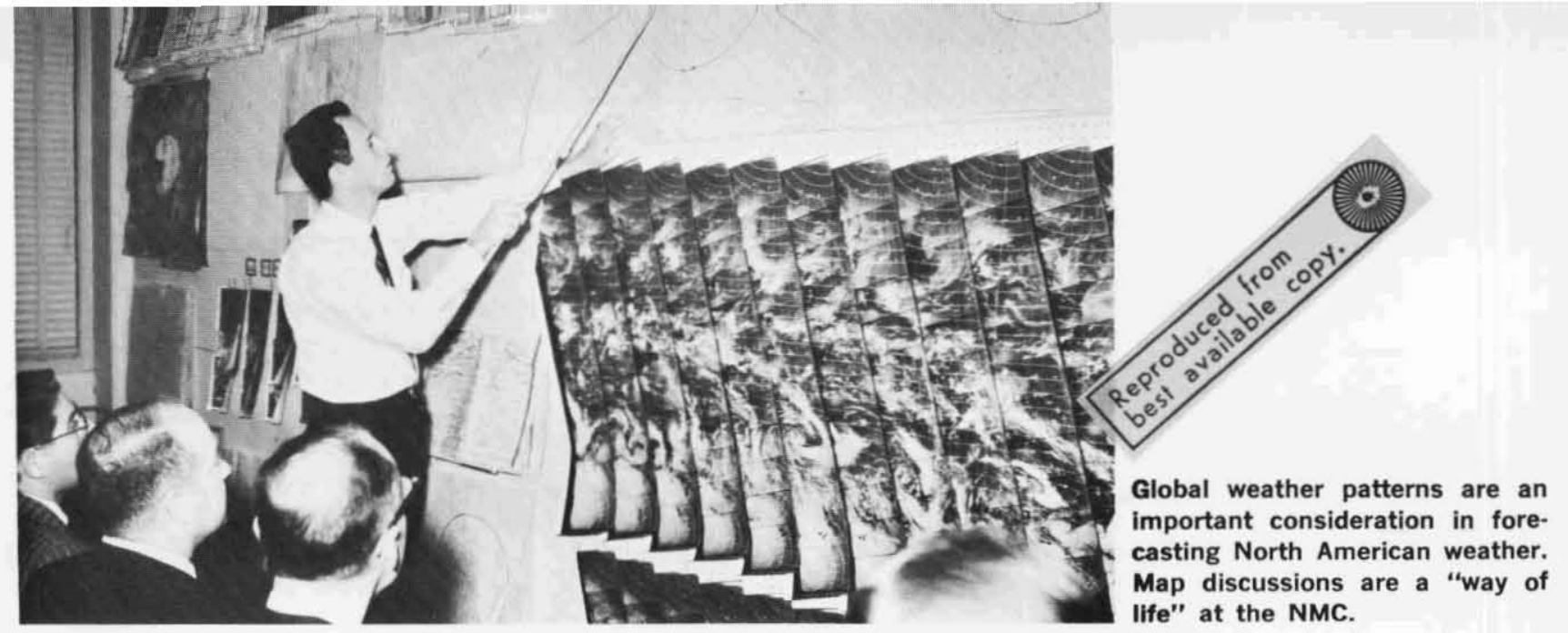

reason that output products of the WMCs and RMCs cannot be delivered to the users in a timely manner. A concerted effort has been made through the WMO Voluntary Assistance Program to overcome deficiencies, and it appears that by the end of the next 4-year cycle, this problem area will be considerably reduced. The GTS is organized on a three-level basis: the Main Trunk Circuit (MTC) connecting the three WMCs; the Regional Telecommunications Network; and the National Telecommunications Network.

The principle function of the MTC is to ensure rapid and reliable exchange MAIN TRUNK of the observational data, including satellite information in digital form, required CIRCUIT AND for analyses and forecasts on a global scale and of the processed information ITS BRANCHES issued by the WMCs.

The worldwide MTC now operates primarily in a low-speed transmission mode. The United States operates, as part of its MTC commitments, three international circuits for the exchange of meteorological data. These circuits are between Washington and terminals at Tokyo (Japan), Offenbach (Federal Republic of Germany), and Brazilia (Brazil). The circuit between Washington and Tokyo was upgraded to high-speed operation on November 24, 1970. The WashingtonOffenbach circuit will be changed to a Washington-Bracknell, England, circuit and upgraded to high-speed operation later in 1971.

Regional Telecommunications Networks are designed by each of the six regional areas of the WMO to meet the needs of the national meteorological services of that region. The basic design concept is an integrated system of point-topoint circuits for the collection, reception, and transmission of meteorological information. Within this concept, the United States operates a long-line network of radio and cable circuits to exchange meteorological information between the United States and other countries in the region. One high-speed link exists between Washington and Toronto, Canada. The bulk of the traffic involves surface and upper air data.

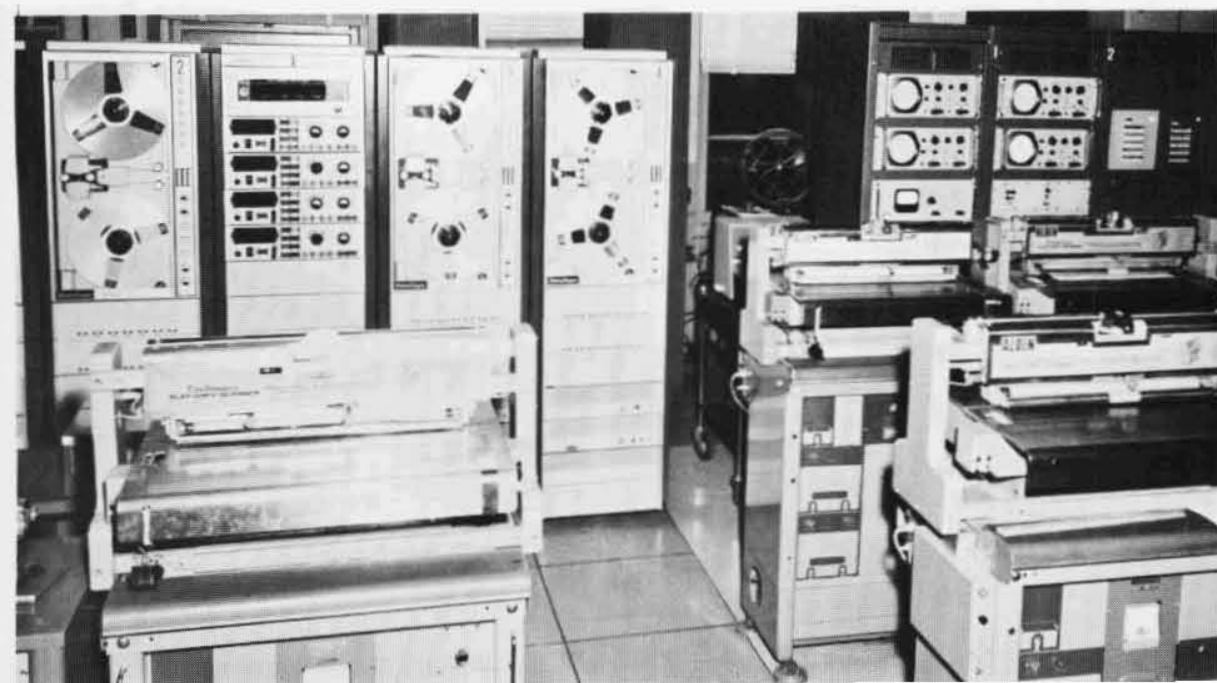

\section{REGIONAL}

NETWORKS

Facsimile equipment and magnetic tape recorders used for the transmission of meteorological information. 
The United States, through the WMO Voluntary Assistance Program, has provided support to five countries for the implementation of their responsibilities under the Regional Networks and plans to continue this effort.

National The NMCs, under the World Weather Watch Plan, are required to complete NETWORKS the collection of observational data originating in their countries as soon as possible to meet the 2-hour time limit for receipt of these data at the WMCs.

A long-line teletypewriter system is the principal means for collecting and distributing observations and forecasts in the conterminous United States. The teletypewriter networks are connected to a high-speed express circuit which is controlled by a weather message switching center. Facsimile systems are also used widely to distribute weather maps and satellite data.

Three countries are receiving support from the United States, under the WMO Voluntary Assistance Program, in implementing their National Networks. Telecommunications equipment is being provided by WMO Members through the WMO Voluntary Assistance Program for Regional Telecommunication Hubs at locations in Brazil, United Arab Republic, Kenya, India, Czechoslovakia, Senegal, Thailand, Nigeria, Iran, and Venezuela.

Voluntary Assistance Program
Support to developing countries to meet their commitments under the World Weather Watch and thereby to gain the maximum benefit from the program has been effected through national resources; bilateral and multilateral meteorological assistance programs; the United Nations Development Program; and the WMO Voluntary Assistance Program. The United States has provided support under all four of these programs and is planning to continue this assistance.

As one means of support to developing countries to implement their responsibilities under the World Weather Watch Plan, the WMO Voluntary Assistance Program was established by the Executive Committee of the WMO in 1967. The Voluntary Assistance Program is maintained by voluntary contributions from developed and developing countries for the purpose of satisfying requests of developing countries for assistance in implementing the World Weather Watch Plan. Under the Program, contributions may take the form of financial payments or through donations of equipment and services.

As of August 31, 1970, 91 Member States of the WMO have submitted a total of 288 requests for assistance in the implementation of projects in their areas of responsibility under the World Weather Watch Program. Of these requests, 112 have been fully or partially satisfied under the Voluntary Assistance Program. As the scope of the World Weather Watch Program is modified to include added emphasis to the global monitoring of atmospheric pollution and to the development of mathematical models for assessing the consequences of growing amounts of this pollution, additional requests for assistance under the Voluntary Assistance Program are anticipated.

In FY 70 and in FY 71, the U.S. contribution to the WMO Voluntary Assistance Program amounted to $\$ 1.5$ million. This amount provided a cash contribution of $\$ 150,000$ on a matching basis and $\$ 1,350,000$ in equipment and services for projects selected by the United States.

Under equipment and service projects, funds are also made available to provide scholarships to U.S. universities, enabling personnel from developing countries to obtain training leading to basic academic degrees in meteorology. The total U.S. effort to date has provided equipment and service support to 29 countries and 43 projects, including 16 scholarships awarded to students from developing countries.

Contributions from other nations to the Voluntary Assistance Program cash fund and the equipment and services support has been substantial. A total of approximately $\$ 1,000,000$ has been pledged or contributed by 50 countries (including the United States) to the cash fund; some of this amount has been provided by several of the developing countries themselves. The cash fund is used to supple- 


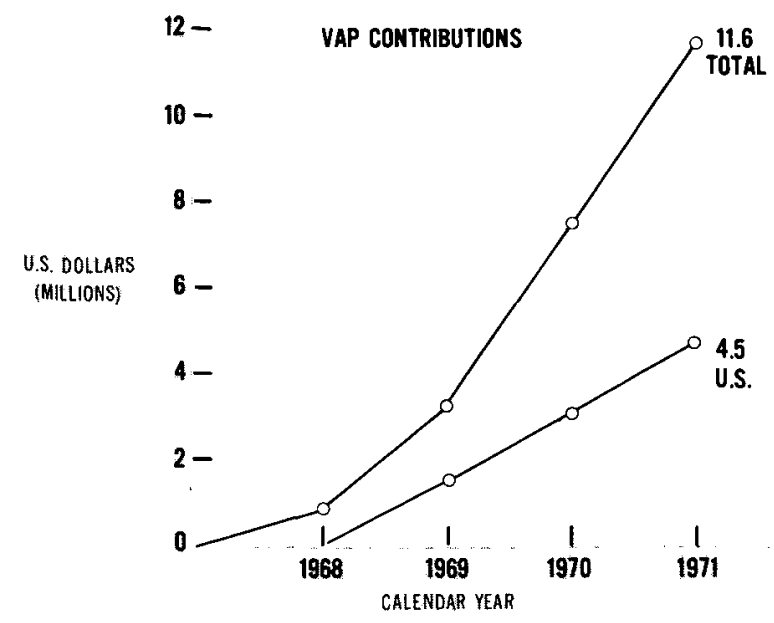

Assistance Requested

91 GOUNIRIES

288 E\&S PROEECTS INCLUDING

71 TRAINING PROIECIS (229 STUDENTS)

\section{Assistance Pledged}

50 COUNTRIES

112 E\&S PROJECTS INCLUDING

41 TRAINING PROJECTS (67 STUOENTS)

U.S. Assistance

29 COUNTRIES

43 E\&S PROJECTS INCLUDING

16 TRAINING PROJECTS (16 STUDENIS)
Contributions to the WMO Voluntary Assistance Program by the U.S. and other nations for the years 1969-71.

ment the Voluntary Assistance Program equipment and services support in critical areas. Many of the countries providing cash have also contributed support for 71 equipment and service projects. In addition, 67 students are being supported for a period of approximately 4 years each under 41 training projects.

This Program has provided an excellent method for all the developed nations of the world to work in a spirit of cooperation and friendship in assisting the developing countries. The United States, through the Department of State, plans to continue this most important effort.

The Global Atmospheric Research Program (GARP) of the World Weather Program is designed to help provide mankind with very substantial improvements in weather prediction services. Just as important, GARP is vital in providing a quantitative basis for the assessment of the consequences of man's pollution on the global atmosphere.

Intensive planning activities, both nationally and internationally, have resulted in several recommended programs for GARP. Much of this has already been covered earlier in this Plan. The program over the next few years will focus on: $\square$ Mathematical modeling and simulation of the atmosphere.

$\square$ Assessment of the effects of man's pollution on the atmosphere.

$\square$ Implementation of the international tropical experiment in the Atlantic during 1974.

$\square$ Planning for an international global observational experiment in 1976 or 1977.

The success of the Program will require the cooperation of several Federal agencies as well as many universities and private industry. The U.S. Committee for GARP of the National Academy of Sciences is composed of scientists who provide advice to the Government on the overall Program and recommend specific research and field programs needed to attain the objectives of GARP. Support for the Committee is shared jointly and equally by the Department of Commerce and by the NSF.

Computer power is a key element in providing and improving short- and long- Mathematical range weather predictions, in assessing the consequences of man's pollution on Modeling and environmental quality, in accelerating progress toward understanding and Simulation simulating the atmospheric processes, and in developing a capability to modify the weather. The development of a national capability to meet this critical computer power need over the next 5 years is the purpose of the Computer Plan for Operational Forecasting and Atmospheric Modeling Research, published in September 1970 by the Federal Coordinator for Meteorological Services and Supporting Research.

\section{GLOBAL}


Computer performance for the years 1953-70 and projections for 1971-76. The computer performance requirements, as estimated at the Stockholm GARP Study Conference in 1967 and indicated on the chart by should be reached by 1972 .

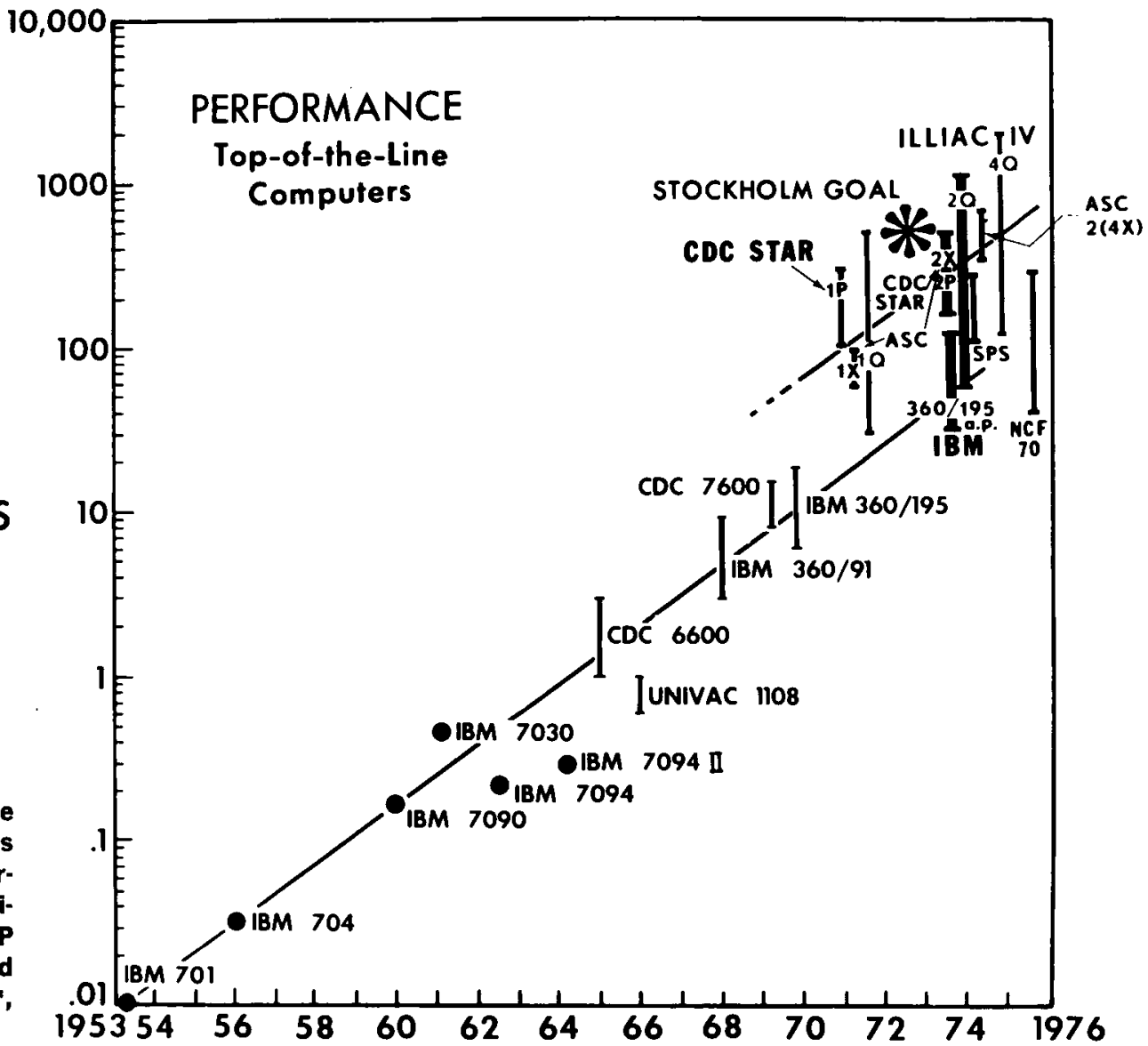

The GARP Study Conference held in Stockholm, Sweden, in 1967 and cosponsored by the World Meteorological Organization (WMO) and the International Council of Scientific Unions (ICSU) substantiated a need for increased computer power and established a goal for computers with speeds of about 500 million instructions per second by about 1972 . The accompanying chart shows the performance of various computers as a function of time and also projects a cluster of potential computers being developed by industry that will meet the Stockholm Conference goal.

In its Plan for U.S. Participation in the Global Atmospheric Research Program issued in May 1969, the National Academy of Sciences reiterated the essential need for computers with speeds of at least 100 times faster than the speeds of the most powerful computers in common use today.

The spectrum of atmospheric motions now being addressed includes characteristic time and space scales that range from the order of seconds relevant to turbulent exchange processes to the order of centuries indicative of long-term climatological changes. Various numerical models exist within various research groups that employ a number of these space-time resolutions. A large number of experiments have been identified as necessary to gain greater insight into the problems that GARP has defined. Present limited computer capacity has permitted only a few of these experiments to be accomplished. More importantly, some significant experiments are not feasible unless more advanced computer systems become available. 
A cooperative effort among the research groups of the Departments of Commerce and Defense, NASA, and NSF has produced the concept of Centers of Program Emphasis through which specific key elements of work have been assigned to respective groups. This concept and its implementation are discussed in the Computer Plan for Operational Forecasting and Atmospheric Modeling Research.

An integral part of GARP is research associated with the inadvertent modifica- Improved tion of the atmosphere by the forces of man. Atmospheric pollution is a global Assessment problem; and the United States, as a participant in the World Weather Program, of has a responsibility to join with the other nations in measuring, predicting, and Atmospheric monitoring the long-term global effects of pollution. The Department of Com- Pollution merce, Environmental Protection Agency, NASA, and NSF are participating in the many aspects of the planning and conduct of a monitoring program for the pollutants which are of significance to the global problem. Similarly, these agencies are conducting research to describe the chemical and physical processes affecting the transport and fate of these pollutants. The particular problem related to aircraft emission effects is being addressed primarily by the Department of Transportation.

Most of the energy received from the sun, which drives the atmospheric circu- International lation of the globe, is used to evaporate moisture over the oceans, especially in the Tropical tropics. As the evaporated moisture condenses into clouds, latent heat is released Atlantic into the air; it is this latent heat which drives the atmospheric circulation. The Experiment mechanisms by which the small clouds become concentrated in cloud clusters and by which the energy released by cloud clusters is fed, in turn, into the large-scale tropical circulation and into the circulation patterns at higher latitudes are not well understood. Equally as little understood is the manner by which some of these local atmospheric circulations develop into giant tropical disturbances or hurricanes. The highly important tropical experiment is programmed to take place in the Atlantic in 1974 to provide an understanding of these mechanisms.

The observational phase of the tropical experiment will be to determine the interactions between four scales of motion as follows:

$\square$ Scale A: the large wave-scale (characteristic size of the order of 1,000 to 10,000 kilometers; very long lifetimes).

$\square$ Scale B: the scale of cloud clusters (characteristic size of the order of 100 to 1,000 kilometers; lifetime of the order of 1 to 5 days).

$\square$ Scale C: the meso-convective scale (characteristic size of the order of 10 to 100 kilometers; various types of characteristic life cycle).

$\square$ Scale D: the scale of convective cells (characteristic size of the order of 1 to 10 kilometers; characteristic time of the order of a few hours).

The tropical experiment is being designed to focus upon the interaction between large-scale atmospheric disturbances, typically thousands of kilometers in extent, and organized deep cumulus convection. Two somewhat different approaches to the problem will be taken. On the one hand, improved physical understanding of the mechanisms by which the interactions take place will be sought. On the other, attempts will be made to parameterize the collective effects of the convection upon the larger scale fields which can be modeled explicitly using computers. Provisions for conducting simultaneous oceanographic investigations will be included in the design of the tropical experiment.

In conjunction with the tropical experiment and in preparation for the First GARP Global Experiment, an integrated systems test is contemplated as an exercise in data acquisition, communications, and processing. Such a Data Acquisition Test could be conducted in the 1973-74 time period, making use of observational and communication facilities available at the time, to include operational and research satellites, operational surface and upper air networks, research balloon 
Ships, such as the Researcher, will provide oceanographic and meteorological observational data for the tropical experiment.

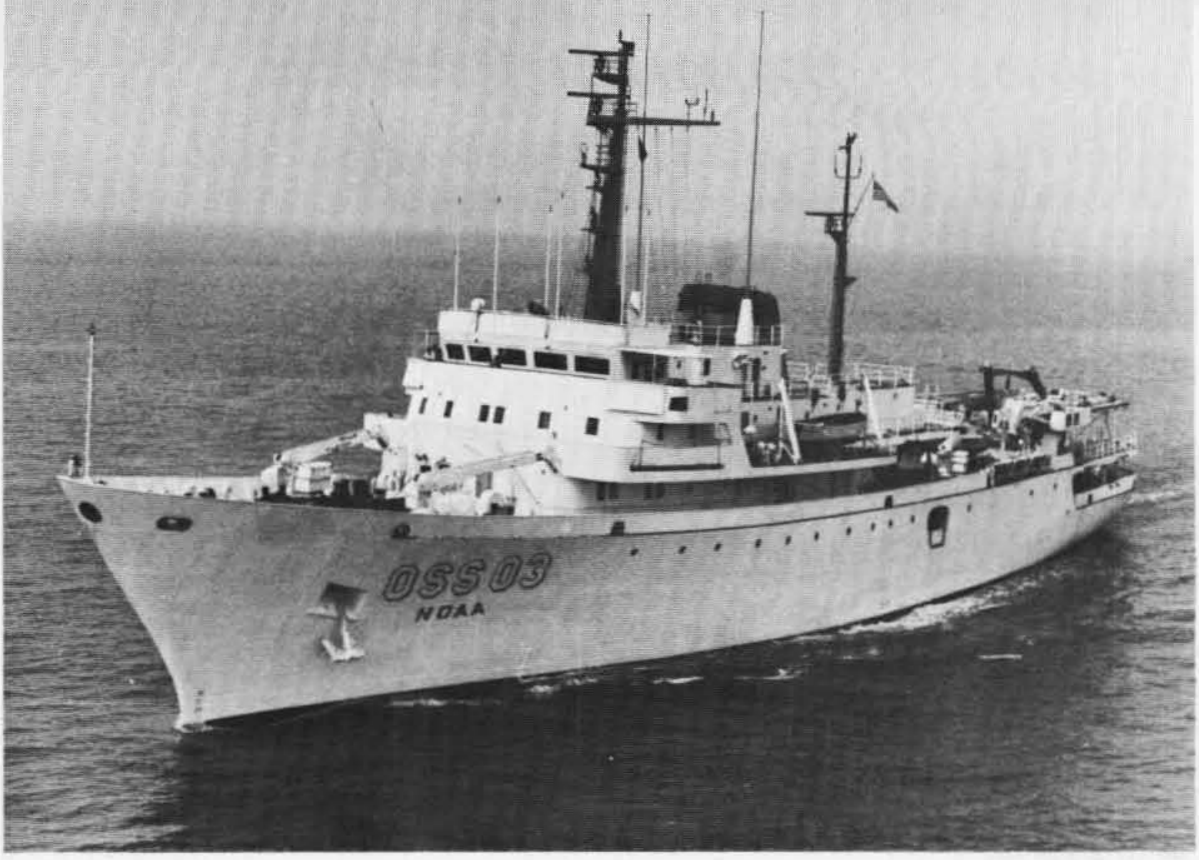

systems, and to the extent possible, the network of special observations established for the tropical experiment. Planning Unique advances have been made during the last few years in the development
for the of technology required to obtain global observations that are so essential if the Global concept of GARP is to be realized. The improved sensors flown on polar-orbiting Experiment satellites to obtain the vertical distribution of temperature in the atmosphere have been very successful. Analysis of data obtained from geostationary satellites has demonstrated that wind observations can be derived at low and high cloud levels from sequential photographs of cloud patterns.. In addition, considerable progress has been made in the development of buoys and horizontal-sounding balloons. Further development and testing of the capability of such platforms are planned within the United States.

A First GARP Global Experiment is being seriously considered, nationally and internationally, for 1976 or 1977. The World Weather Watch observing systems of conventional and satellite data in existence at the time will be used as a base and will be augmented only to the extent necessary to satisfy the requirements of the Global Experiment.

The detailed design of the Experiment is now being pursued nationally under the leadership of NASA, with the assistance of other agencies.

Clear Air For several years, the Departments of Defense and Transportation, NASA, Turbulence and NSF have been developing a coordinated program to obtain a better understanding of the causes of clear air turbulence. Areas associated with clear air turbulence may be sources and sinks of energy and thus areas of energy transformation in the atmosphere. As such, clear air turbulence is an important aspect which should be investigated as part of GARP. The Federal Plan for Clear Air Turbulence was published in November 1969; and the agencies concerned with clear air turbulence are continuing development of aircraft sensor instrumentation and other equipment and techniques associated with the measurement, detection, and prediction of clear air and other turbulence.

The gathering of data for World Weather Watch operations and GARP research requires extensive observing systems with a wide range of meteorological platforms and sensors.

The global observing system must provide adequate initial data for large-scale atmospheric prediction models. In general, adequate data are available from the landmasses of the Northern Hemisphere. The vital need is for data of com- 


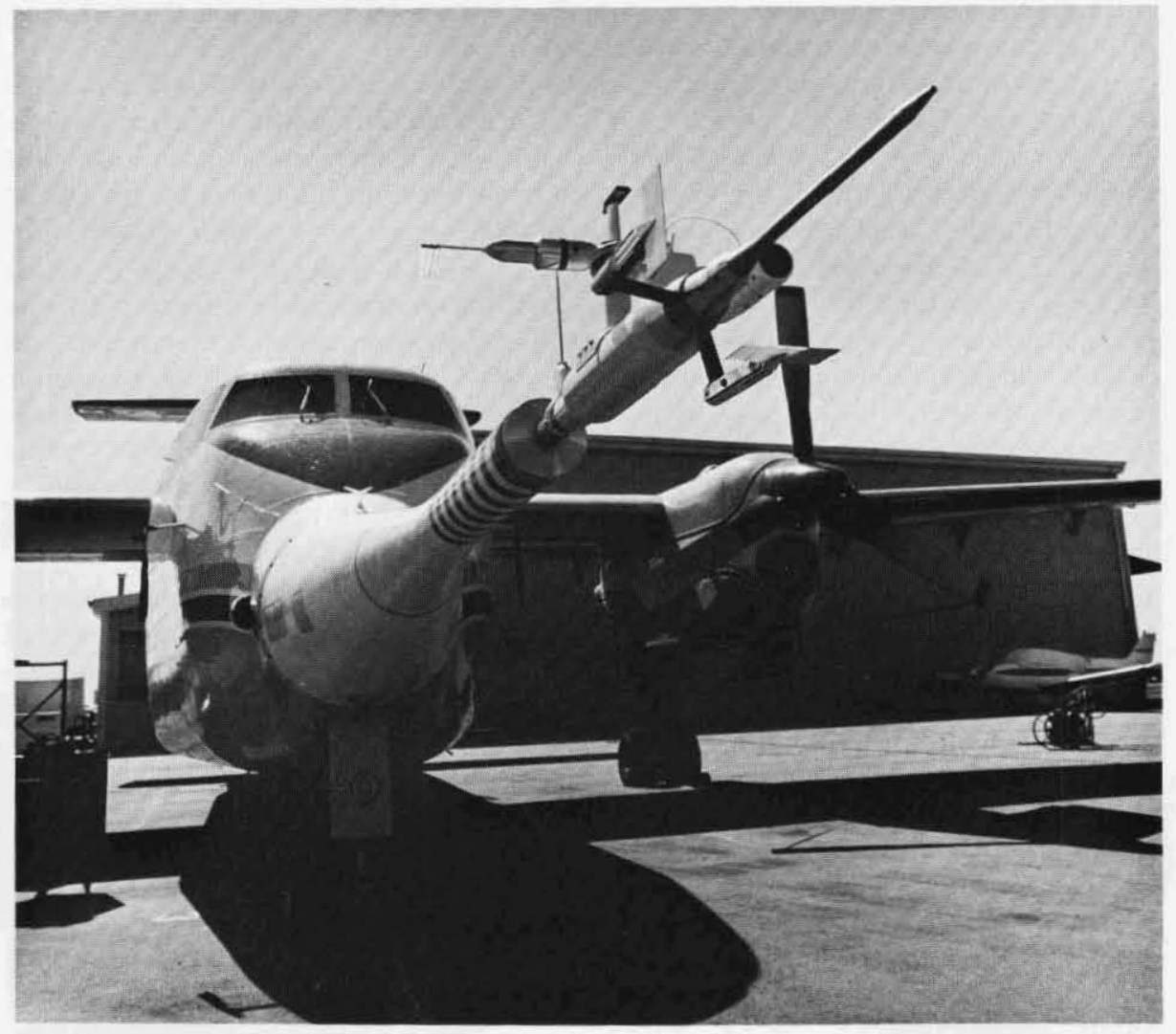

parable quality, density, and frequency from the tropics, the ocean areas of the Northern and Southern Hemisphere, and the land areas of the Southern Hemisphere.

With regard to the tropics, wind information at required upper levels is of most concern. As a means of providing these data, potential systems under study or development are:

$\checkmark$ Satellite-carrier balloon system having wind dropsonde capability for measuring winds at several levels.

Additional upper air equipment for use on moving ships.

$\square$ Determination of winds by movement of clouds in sequential pictures observed by geostationary satellites.

$\square$ Aircraft dropsonde (Omega systems).

With regard to the data sparse ocean areas of the Northern and Southern Hemisphere (exclusive of the tropics), the following systems are under development or consideration:

$\square$ Drifting and moored buoys (surface data only).

Additional upper air equipment for use on moving ships.

Satellite temperature-sounding system.

$\square$ Aircraft dropsonde (Omega system).

With regard to the landmasses of the Southern Hemisphere, the acquisition of data in this data sparse area is limited by problems concerning communications. New technology is not required to remedy this deficiency; rather, the greatest need is to obtain adequate resources to implement the total communication systems required. The Voluntary Assistance Program is being used extensively for this purpose.
A new airborne turbulence-measuring system for studies on the motions and transfers of energy in the atmosphere is mounted on NCAR's Buffalo aircraft. 
The acquisition of marine meteorological data is being enhanced by the use of buoy platforms for automatic weather stations.

A number of nations have conducted considerable research work and a number of successful trials on the use of buoy platforms for automatic weather stations. Five countries already use buoys for the collection of meteorological information. Eight additional countries are expected to have buoys in operation by the end of $1971 ; 13$ other countries are planning to use buoys in the near future. The National Data Buoy Development Program of NOAA is the U.S. focus to satisfy national needs for this type of platform. Drifting or moored buoys are platforms being considered, along with suitably equipped moving ships, for acquiring the needed surface reference-level data over the Southern Hemisphere to extract temperature - as a function of geopotential-from the satellite remote temperatures-sounding system. Use of a constant-level, horizontal-sounding balloon system is being considered as a data acquisition platform for a second reference level.

The development of a satellite and horizontal-sounding balloon system is being pursued by the National Center for Atmospheric Research (NCAR) in conjunction with NASA. Included here is developmental work on sensors and on materials for use in constant-level balloon systems. The effort involves the development of an improved location technique, using a simple lightweight vertical magnetometer and radio altimeter in conjunction with the previously used sun-angle sensor, and of dropsondes from balloons for measuring winds at several levels.

Beyond the tropical regions, the polar-orbiting satellite instrumented with vertical-sounding sensors and a data collection capability has great potential for providing adequate initial data for large-scale atmospheric forecast models. Even

Horizontal-sounding balloon for measuring winds on a global scale at a constant density level.

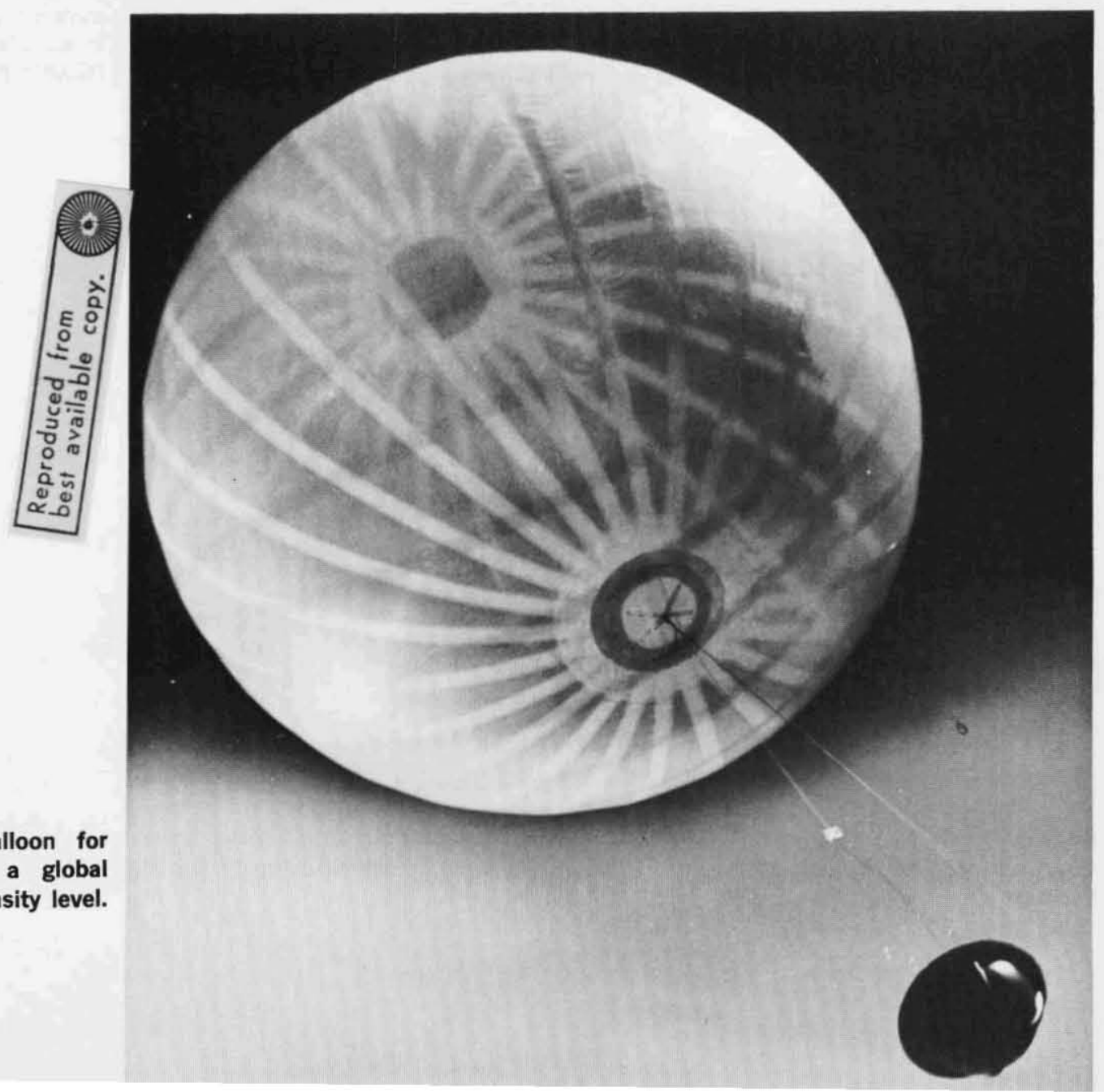


in the tropics, the synchronous meteorological satellite offers considerable promise for obtaining wind data from the movement of clouds in sequential pictures.

Meteorological research conducted by NASA and the Departments of Commerce and Defense provides the technology and data utilization techniques necessary to meet the major long-term objectives set by these Federal agencies in their planning for a coordinated meteorological satellite program.

Developments necessary for achieving the first objective of global-viewing were largely achieved with ITOS spacecraft. Efforts continue toward improved resolution, location, and display. Attention will also be given to the development of methods for measuring additional environmental properties, to the solution of data and product distribution problems, and to the improvement of ground stations.

A second objective of the National Operational Meteorological Satellite System (NOMSS) includes both continuous viewing and the collection and relaying of meteorological data from instrumented platforms such as buoys, ships, automatic stations, aircraft; and balloons. NASA conducts experiments in support of this objective with its Nimbus and Applications Technology Spacecraft (ATS) series. In addition, NASA is funding and developing the Synchronous Meteorological Satellite (SMS) prototype for the Geostationary Operational Environmental Satellite (GOES).

The SMS A and B prototype spacecraft, scheduled for launch in 1972 and 1973, respectively, will be the forerunners for the GOES system which will provide nearly continuous viewing of global cloud cover except for the polar regions, plus data collection and relay capability. SMS A, to be positioned over the Equator at about $100^{\circ} \mathrm{W}$. longitude, will cover North and South America and much of the Atlantic and Pacific Oceans. Growing out of concepts proven in the ATS and other programs, SMS/GOES will yield new and improved data for weather prediction, environmental survey, and timely warning of hazardous environmental conditions.

Research and development for precise quantitative atmospheric sounding, the third program objective of NOMSS, are emphasized in NASA's Nimbus program for developing sensing techniques.

In addition, the Departments of Commerce and Defense conduct a wide variety of studies on applications of meteorological satellite data to improve services. Major efforts will be directed to developing new methods for using satellite data in environmental analysis and forecasting. The radiative and optical properties of atmospheric constituents will be studied to aid in the design of satellite-borne sensors and in the interpretation of data from these sensors. Special attention is given to the interpretation and validation of new data acquired by operational and research satellites and to the application of these data as inputs to numerical analysis and forecasting.

The Omega navigation-aid system for obtaining upper level wind information is undergoing tests by NOAA, the Coast Guard, and the Department of Defense. This system has applicability for obtaining upper wind data from fixed and moving ships and for adding the windfinding capability to the aircraft dropsonde system. The Omegasonde promises to be a practical system requiring no elaborate antennas or stabilized reference platforms and therefore can be installed readily on moving platforms.

For the detection and monitoring of the atmospheric turbulence phenomena. the Department of Transportation conducts an analysis and instrumentation development program.

It is important that a systems design be conducted to determine the optimum mix of the proposed observational sensors and platforms for meeting the World Weather Watch and GARP requirements. 


\section{The United States Program for Fiscal Year 1972}

The World Weather Program comprises three areas of effort: (1) World Weather Watch Implementation; (2) Global Atmospheric Research Program; and (3) Systems Design and Technological Development.

The following conventions have been used to identify the funds for U.S. activities in support of or contributing to the World Weather Program:

$\square$ Budget figures without parentheses are for projects specifically in support of the World Weather Program.

$\square$ Budget figures enclosed in parentheses have been programmed by the agency primarily to meet immediate mission needs, but at the same time fulfill a requirement of the World Weather Program, and would be included even in the absence of U.S. participation in the World Weather Program.

$\square$ The total budget for FY 72 is indicated for activities under the Global Atmospheric Research Program (GARP) and the Systems Design and Technological Development.

$\square$ For the World Weather Watch Implementation, only the increased obligational authority being requested is indicated in FY 72 activities, except for the operational satellite program and the Voluntary Assistance Program in which the total budget is indicated.

WORLD

In FY 72, the major thrusts of the U.S. effort to implement the World Weather

WEATHER WATCH Watch include improving the existing operational satellite system; developing the IMPLEMENTATION next generation operational satellite system; establishing an atmospheric monitoring capability; increasing computer processing capacity; and providing assistance to the meteorological services of developing nations.

Satellite Satellites of the current Improved TIROS Operational Satellite (ITOS) series Observing will continue to serve for several years as the polar-orbiting observing spacecraft

DOC of the National Operational Meteorological Satellite System (NOMSS). Studies

$(\$ 31,537,000)$ to improve the current system will be continued by NASA in FY 72, leading to NASA

$(\$ 14,600,000)$ the development of a third-generation polar-orbiting meteorological satellite system for the mid-1970's time period.

Design and development by NASA of the spacecraft for near-continuous viewing of the atmosphere, the Synchronous Meteorological Satellite (SMS), will be completed in FY 72, with first launch scheduled for July 1972. The SMS is the prototype of the Geostationary Operational Environmental Satellite (GOES) system which will meet the second of the objectives of the NOMSS.

The Department of Commerce is planning increased obligations of $\$ 5,963,000$ in FY 72 over the FY 71 program, for a total of $\$ 31,537,000$, to procure and operate equipment for the satellite system. This increased amount is to continue the construction of the ITOS F and G and the GOES A spacecraft; to modify the ITOS D and E spacecraft; to continue the procurement of ITOS launch vehicles; to provide staff and equipment to process, disseminate, and display 
satellite data and products; to procure additional equipment and staff for the GOES Command and Data Acquisition Station initiated in FY 70; and to procure telemetry and communications equipment for data collection relay. A Vertical Temperature Profile Radiometer (VTPR) will be added in 1972 to the ITOS series to provide routine observations of atmospheric temperature profiles throughout the world.

In FY 72, the Department of Commerce plans to improve the existing opera- Global tional capability of the station at Mauna Loa Observatory, Hawaii, to monitor Monitoring of atmospheric pollution, and to establish and implement a new global baseline Atmospheric monitoring station at a remote Arctic site. Also, ice nuclei counters will be Composition installed at seven National Weather Service stations, geographically distributed DOC over the United States. Funding in the amount of $\$ 410,000$ is budgeted in FY 72. $\$ 410,000$ Research activities in global monitoring are reported under the GARP section, EPA below.

$(\$ 10,000)$

The Environmental Protection Agency (EPA) is providing sun photometer equipment for long-term monitoring of atmospheric turbidity at 10 NOAA National Weather Service stations. Precipitation samples will also be collected at these regional stations for chemical analysis.

The Department of Commerce is continually striving to improve its capability Processing in weather predictions. The quality of the predictions is dependent upon the DOC characteristics and fidelity of the mathematical models used. In FY 72, an increase $(\$ 1,100,000)$ of $\$ 1,100,000$ is budgeted to provide additional computer time to test, maintain, operate, and monitor new forecast models used at the World Meteorological Center (WMG) in Washington.

The Department of State provides funds for the Voluntary Assistance Program Foreign from the annual Foreign Assistance Act appropriation. The funds are administered Assistance by the Department of Commerce. An amount of $\$ 1,500,000$ has been in- DOS cluded in the FY 72 Foreign Assistance Act appropriation request for the U.S. $\$ 1,500,000$ contribution to this Program in Calendar Year 1972.

Progress is being made in the planning, design, and implementation of research GLOBAL field projects for GARP. Further, research on computer modeling and simulation ATMOSPHERIC of the atmosphere, on global monitoring of atmospheric constituents, and on RESEARCH supporting hardware systems will be accelerated in FY 72. A tropical experiment PROGRAM in the Atlantic is planned for 1974 .

The analysis of the observational data collected during the Barbados Oceano- Experiments graphic and Meteorological Experiment (BOMEX), initiated during FY 71, will and continue in FY 72. This analysis phase is supported by the Department of Com- Analysis merce, AEC, NASA, and NSF, as well as several universities and the National DOC Center for Atmospheric Research (NCAR).

The Atomic Energy Commission (AEC) plans further to instrument and NSF modify a deep-sea buoy used during BOMEX and to make demonstration scientific measurements over lakes behind Columbia River dams in the Pacific Northwest States. Measurements on an alternate system will be made over Lake Michigan from towers, rafts, or buoys. These measurements are of turbulence, meteorological profiles, radiation exchanges, and other parameters pertinent to the air-sea exchange.

The NSF plans continued support to the university community in its analyses of the BOMEX data. Much of the observational data collected by university groups have been processed and the analysis begun. The NCAR of NSF is also involved deeply in the GARP effort. The NCAR plans to serve as an active communications link to the university scientists for GARP activities. Additional time and effort for planning also are required by the NSF staff.

The Department of Commerce and the NSF will continue to share the funding 
of the U.S. Committee for GARP within the National Academy of Sciences, including a small permanent staff to assist the Committee.

In FY 72, the Department of Commerce plans to conduct research and development for the design, construction, and testing of prototype data acquisition systems (sensing, recording, and preliminary data processing) required for oceanographic, biological, surface meteorological, and boundary layer measurements from ships taking part in the tropical experiment. Other effort is required to begin the formulation and design of the scientific data reduction and analysis, the computer programs, and the communications and logistics to support this field experiment. Plans are also being made for the processing and analysis of research data to be obtained on clear air turbulence.

Also in 1972, major items of equipment essential to the tropical experiment are to be procured by Commerce for installation on NOAA ships and aircraft. The lead times are such that these items cannot be obtained by 1974 unless procurement is begun in FY 72. The items are two shipboard upper air sounding systems, one inertial platform, and associated research instrumentation for installation on the NOAA C-130 aircraft.

NASA will continue research and development efforts for the planning, implementation, and logistical support of GARP field experiments. Studies will be conducted of data management techniques for the real-time acquisition, processing, and application of data for use in the tropical experiment and in the First GARP Global Experiment (FGGE). Analysis will be made of the feasibility, usefulness, and suitable objectives of a Data Acquisition Test. Proposed observing systems will be analyzed to define those areas where redundancy of observations would be particularly useful and to determine the degree of redundancy necessary. Initial planning efforts for the FGGE will be conducted, with support from NOAA.

Atmospheric Modeling and Simulation DOC $(\$ 4,014,000)$ NSF $\$ 1,250,000$ $(\$ 4,289,000)$ NASA $\$ 750,000$ DOD $(\$ 5,436,000)$
Several Federal agencies, some universities, and NCAR are continuing their efforts on modeling of the atmosphere and on simulation of the atmosphere's motions and conditions by numerical models. The models are being refined to provide greater vertical and horizontal resolution and to incorporate the influence of the oceans and of atmospheric turbulence. Increased senior scientific staff is required to plan and execute vital experiments using the substantially increased computer power planned for installation in FY 71 and FY 72.

The major emphasis in NSF efforts during FY 72 will be in intensive and experimental applications and in basic research through models on turbulence and convective phenomena. A larger computer funded by NSF should be in operation at NGAR during FY 71.

Within the NSF program supporting GARP, university numerical model studies of various types will continue to be funded. Examples of the programs being supported include model studies of air-sea interaction using data from BOMEX, prediction of regional weather involving the tropics, more sophistication of the modeling of the general circulation, parameterization of solar energy distribution, prediction of baroclinic flows, and studies of circulations produced by the release of salt into the Arctic Ocean. The NSF is also supporting investigations pursuing the questions of how predictable is the atmosphere and how far in advance can the state of the atmosphere be predicted.

Th NCAR will continue its current efforts on observing systems simulation during FY 72. Two projects have been identified that principally evaluate the usefulness of balloon and buoy observations.

In FY 72, the Department of Defense will continue its developmental efforts on a global atmospheric model. Major emphasis will be placed on the intensive applications of climatic change as a result of any large-scale climatic modification. These efforts include the study of the effects of friction, topography, moisture, and 
radiation; the isolation and study of important physical processes that determine the nature of organized atmospheric circulations; the study of the coupling of the atmosphere-ocean environment; and the investigation of sea-air interaction and energy balance.

In the Department of Commerce, the major emphasis will stress experimental applications and basic research through models on large-scale, medium-scale, and extended-period forecasts. To support this intensive research, the Department of Commerce plans to lease an advanced computer with speeds substantially in excess of those currently in use. The effort in FY 72 will also include experiments to represent more accurately the effects of fine-scale processes and the interaction of oceanic and atmospheric circulations; to simulate observing systems so as to determine the characteristics of the optimum system, including the operational analysis and prediction systems designed to utilize these observations; to improve the overall accuracy of environmental prediction, including hurricanes and other severe storms; and to extend the time range of large-scale predictions from 3 days to 2 or more weeks.

The major emphasis in NASA will be in mesoscale and large-scale intensive applications of observing systems simulation. Mathematical modeling and simulation studies, conducted at the Goddard Institute for Space Studies, will be continued in FY 72 to develop models of atmospheric behavior and to define optimum observing-system parameters.

The Department of Commerce is planning to procure, install, and test a prototype of a lidar equipment for measuring the vertical distribution of particulates in the atmosphere; and to conduct analysis and interpretation of data from environmental monitoring stations for determining significant trends.

The Environmental Protection Agency (EPA) plans to conduct studies of the distribution of pollutants in the atmosphere and to continue the development of refined measurement techniques. Efforts are being continued to develop and to improve remote sensing equipment for determination of profiles of particulates and for yielding data that can give an estimate of mixing depth and thermal stability of the lower atmosphere. Studies of the chemical and physical processes in the atmosphere which affect pollution dispersion and distribution will also be conducted.

The NSF plans to continue its support of the Mauna Loa and New Zealand carbon dioxide monitoring stations. It is anticipated that planning will be accomplished during FY 72 for establishing another carbon dioxide monitoring station on the Antarctic continent. A study of the production of ozone in the lower levels of the troposphere and its interactions with the nitrogen oxide family and other pollutants is also being funded by the NSF.

The NCAR has several other atmospheric chemistry and physics programs underway whose goals are to determine the atmospheric background of trace substances, including radioactivity and aerosols. One of these programs is designed to determine the physical processes effective in modifying the natural atmospheric aerosol-size distribution. Sampling of atmospheric aerosols and the determination of aerosol profiles are a continuing part of this program.

The Department of Transportation is planning research on an environmental program concerning inadvertent weather modification by the supersonic transport (SST) which will determine the effects of stratospheric photochemical reactions, exhaust particulates, and contrails on the atmospheric heat balance as they relate to climatic changes.

Systems design and technological development are essential for the advancement of the World Weather Watch and for the conduct of GARP. Progress is being made, and several agencies are planning increased efforts in FY 72.

\section{Global Monitoring of Atmospheric Composition DOC $\$ 400,000$ EPA $(\$ 175,000)$ NSF $(\$ 250,000)$ DOT $(\$ 4,500,000)$}

SYSTEMS DESIGN AND TECHNOLOGICAL DEVELOPMENT 
Instrument Development DOC

$(\$ 625,000)$

DOD

$(\$ 12,150,000)$

DOT

$(\$ 265,000)$

EPA

$(\$ 30,000)$

NSF

$(\$ 340,000)$
The Department of Commerce is continuing its efforts in the development of navigational aid windfinding equipment; remote sensing of wind, temperature, and precipitation by electromagnetic and acoustical techniques using groundbased equipment; and remote sensing of surface variables from space-based satellites. Also being continued is the development of observing systems required to sense various meteorological parameters automatically which will be operated at remote sites, including coastal areas.

Detailed design and development of instrumentation for aircraft and sensors to be used in GARP Experiments are being continued by NCAR during FY 72. The turboprop DeHaviland C8A Buffalo aircraft has been instrumented with an inertial platform. Additional instrumentation will be provided and tested, particularly for describing the three-dimensional picture of convective patterns and for measuring the turbulent motions in the atmosphere; improved recording for remote field-observing equipment and standardization of sensors for recording of data from multiple aircraft will also be provided.

The Department of Defense is developing sensor instrumentation for aircraft, ships, and automatic weather stations which will contribute to the GARP Experiments and to the World Weather Watch, although not directly a part of either of those efforts. Also, Defense developmental efforts are directed toward the improvement of ground and airborne meteorological sensors and of a central processing system for hurricane reconnaissance aircraft; the feasibility and testing of an air-droppable automatic weather station and radio relay system; the development of airborne refractometer systems for the sensing and recording of atmospheric refractive index profile data; the investigation of sensing techniques for direct measurement from aircraft, including flight testing of an improved hygrometer; and the testing of a mobile weather radar designed to detect, locate, and determine the size, shape, intensity, and movement of precipitation and clouds. Funding for these programs in FY 72 will be $\$ 12,150,000$.

Research in FY 72 will be conducted by the Department of Transportation on hazardous aviation weather to improve techniques and equipment for the detection and avoidance of atmospheric turbulence; to improve measurements of the severity of storms and other hazardous weather; and to provide accurate information and timely warnings of hazardous weather conditions.

Satellite- The NCAR will continue its developmental work on sensors and materials for Balloon use in the Global Horizontal Observing Systems Test (GHOST). Currently Systems NSF $\$ 478,000$ NASA

$\$ 1,000,000$ being undertaken is a Southern Hemisphere experimental observational program, deploying about 50 balloons at the 200 -millibar level $(12 \mathrm{~km})$ to provide wind data for the Indian Ocean-Australia-South Pacific Ocean area. Some funds will also be used to support a 1,000 GHOST-balloons program that is scheduled as part of the Nimbus $F$ spacecraft experiment.

NASA will investigate the feasibility and practicality of employing satelliteballoon systems for the acquisition and transmission of global atmospheric data required for the tropical experiment and the FGGE. A satellite-carrier balloon system, employing releasable dropsondes, will be investigated for the routine determination of vertical profiles of wind, temperature, and water vapor in tropical regions. A test of a super-pressure balloon system incorporating random Doppler-location techniques and a radio-altimeter for height determination will be considered as one means of determining winds, and as an atmospheric reference level over the unpopulated expanse of the Southern Hemisphere. Other techniques for the determination of tropical winds and reference levels will also be investigated.

Buoys With the establishment of NOAA, the Department of Commerce has acquired the buoy development efforts formerly part of the Department of Transportation. The National Data Buoy Development Program is continuing the effort 
in FY 72 toward developing, evaluating, and taking the technical and analytical steps necessary to facilitate a decision to deploy networks of data buoys for satisfying national requirements for data from deep oceans and the coastal areas of North America.

In FY 72, requirements studies will focus on cost analyses to determine the most cost-effective means to satisfy user requirements and to relate the sensitivity of the outcome to various environmental and technological factors; scientific investigations to determine the type and distribution of data required; and assessments of user data requirements which occur as greater knowledge and experience are accumulated.

Advanced developmental efforts will concentrate on the deployment, testing, and evaluation of Engineering Experimental Phase Buoys; the specification and procurement of preprototype buoys; the specification and procurement of lowcapability buoys; the supporting investigations; and the systems engineering, program control, and logistic support. Low-capability buoys, which sense fewer parameters and are either moored or drifting, will be specified and procured for deployment in July 1972.

NASA has a continuing broad program of research and development on meteorological satellites and on associated sensor systems. This program contributes significantly to the World Weather Program.

The Nimbus satellites will continue to provide vehicles for the development and testing of advanced sensors and satellite technology and for the acquisition of environmental data for research purposes. In addition, these satellites have served as platforms for the operational test of improved imaging systems to provide higher resolution coverage of cloud systems.

During FY 72, development and fabrication of Nimbus $E$ and F will be continued and Nimbus $E$ will be launched. The Nimbus E will make the first use from space of microwave spectrometry for the sounding of the atmosphere to provide an improved means for quantitative measurements through cloud and moisture layers. The Nimbus F, to be launched in FY 73, will contribute further advances in microwave-sensing technology and will provide research data for the assessment of global radiation transfers.

The Applications Technology Satellite (ATS) series of spacecraft, designed primarily to test space application concepts and techniques, has provided important contributions to meteorology. Research will continue in FY 72 on the data obtained from these satellites. The next spacecraft in this series of interest to the World Weather Program is the ATS F which will be under development during FY 72 for a launching in FY 73. The ATS F will employ a two-channel high-resolution radiometer capable of providing cloud-cover photography both day and night. The ATS G is planned for a 1975 launch; meteorological experiments are under consideration.

The Department of Commerce plans to improve techniques for deriving tem- Supporting perature profiles from radiation measurements, for processing and analyzing space- Research and acquired data and their integration with data obtained from other sources, and Technology for estimating winds from satellite-acquired temperature fields. Also, Commerce DOC plans to continue systems studies on parameters to be observed and on feasible $\$ 200,000$ measurement methods so as to determine the structure, evolution, dynamics, and $(\$ 1,075,000)$ thermodynamics of medium-scale, convective atmospheric elements; these studies will also provide recommended accuracies, resolution, spacing, and frequency of measurement of the parameters.

EPA is sponsoring a study to determine the feasibility and application of satellite sensors for global pollution monitoring which may be adaptable to the Nimbus satellite series. 
NASA conducts a broad program of Supporting Research and Technology that contributes toward the improvement of meteorological satellite systems, sensors, and scientific applications. Four specific areas are emphasized: theoretical and applied research, sensor and instrumentation development, spacecraft technology, and data processing.

In FY 72, the research and development efforts will continue in various areas that involve analysis and interpretation, sensor evaluation, and sensor development and that include studies in support of GARP. These efforts will include research to optimize techniques for the sensing, processing, and selection of the most appropriate spectral intervals for sounding of the atmosphere. Efforts will continue in the development of microwave techniques for determining the state of the atmosphere and the state of the sea, and for the inference of surface wind fields. 


\section{Fiscal Summary}

The United States has planned activities in FY 72 in all three major areas of the World Weather Program-the World Weather Watch, Global Atmospheric Research Program, and Systems Design and Technological Development. The funding by agency in these three areas is summarized below. Funding is shown for FY 71 and FY 72. Also, the funding is categorized as either direct (specifically in support of the World Weather Program) or indirect (primarily for other agency needs but also fulfilling a World Weather Program need).

$\square$ World Weather Watch

(Thousands of Dollars)

FY $71 \quad$ FY 72

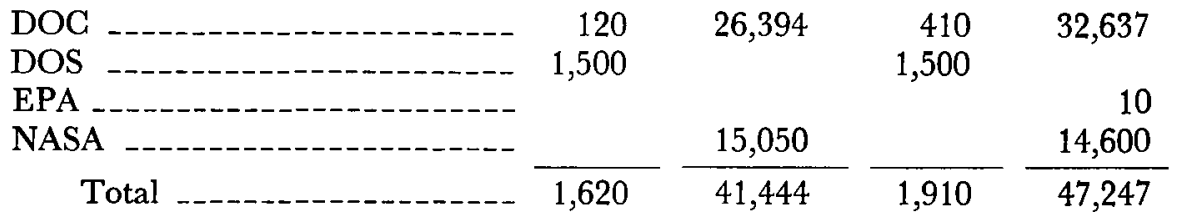

Global Atmospheric

Research Program

AEC

40
850

115

$115 \quad 40$

125

DOC

850

2,314

3,015

DOT

125

4,000

4,014

5,436

4,500

EPA

1,000

1,000

175

NASA

\begin{tabular}{l}
2,000 \\
\hline 3,890
\end{tabular}

$\frac{5,601}{12,170}$

1,500

$\frac{2,500}{8,040} \frac{5,702}{19,952}$

Systems Design and

Technological Development

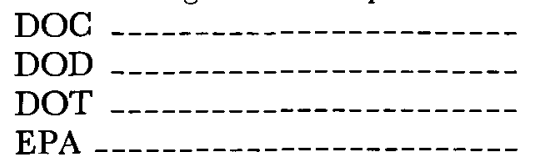

NASA

200

14,694

200

14,700

12,150

130

265

95

110

29,011

29,700

NSF

$\frac{483}{683} \frac{343}{47,358} \frac{478}{1,678} \frac{340}{57,265}$ 